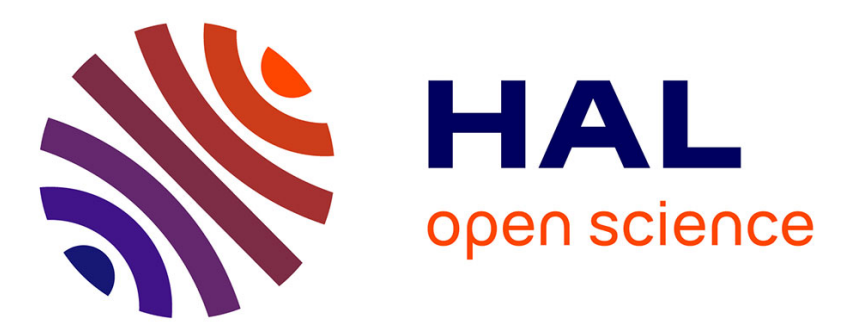

\title{
A scale-entropy diffusion equation to describe the multi-scale features of turbulent flames near a wall
}

Diogo Queiros-Conde, Fabrice Foucher, Christine Mounaïm-Rousselle, H. Kassema, M. Feidt

\section{- To cite this version:}

Diogo Queiros-Conde, Fabrice Foucher, Christine Mounaïm-Rousselle, H. Kassema, M. Feidt. A scale-entropy diffusion equation to describe the multi-scale features of turbulent flames near a wall. Physica A: Statistical Mechanics and its Applications, 2008, 387 (27), pp.6712-6724. 10.1016/j.physa.2008.09.018 . hal-00618066

\section{HAL Id: hal-00618066 https://hal.science/hal-00618066}

Submitted on 25 Feb 2021

HAL is a multi-disciplinary open access archive for the deposit and dissemination of scientific research documents, whether they are published or not. The documents may come from teaching and research institutions in France or abroad, or from public or private research centers.
L'archive ouverte pluridisciplinaire HAL, est destinée au dépôt et à la diffusion de documents scientifiques de niveau recherche, publiés ou non, émanant des établissements d'enseignement et de recherche français ou étrangers, des laboratoires publics ou privés. 


\title{
A scale-entropy diffusion equation to describe the multi-scale features of turbulent flames near a wall
}

\author{
D. Queiros-Conde ${ }^{\mathrm{a}, *}$, F. Foucher $^{\mathrm{b}}$, C. Mounaïm-Rousselle ${ }^{\mathrm{b}}$, H. Kassem $^{\mathrm{a}}$, M. Feidt ${ }^{\mathrm{c}}$ \\ ${ }^{a}$ ENSTA-ParisTech, Unité Chimie et Procédés, 32 Bb Victor, 75015 Paris, France \\ ${ }^{\mathrm{b}}$ LME, Polytech'Orléans, Université d'Orléans, 45072 Orléans, France \\ ${ }^{\mathrm{c}}$ LEMTA, ENSEM-INPL, 2 Av. de la Forêt de Haye, F-54504 Vandoeuvre lès Nancy, France
}

\begin{abstract}
Multi-scale features of turbulent flames near a wall display two kinds of scale-dependent fractal features. In scale-space, an unique fractal dimension cannot be defined and the fractal dimension of the front is scale-dependent. Moreover, when the front approaches the wall, this dependency changes: fractal dimension also depends on the wall-distance. Our aim here is to propose a general geometrical framework that provides the possibility to integrate these two cases, in order to describe the multi-scale structure of turbulent flames interacting with a wall. Based on the scale-entropy quantity, which is simply linked to the roughness of the front, we thus introduce a general scale-entropy diffusion equation. We define the notion of "scale-evolutivity" which characterises the deviation of a multi-scale system from the pure fractal behaviour. The specific case of a constant "scale-evolutivity" over the scalerange is studied. In this case, called "parabolic scaling", the fractal dimension is a linear function of the logarithm of scale. The case of a constant scale-evolutivity in the wall-distance space implies that the fractal dimension depends linearly on the logarithm of the walldistance. We then verified experimentally, that parabolic scaling represents a good approximation of the real multi-scale features of turbulent flames near a wall.
\end{abstract}

\section{Introduction}

In this paper, we present a new geometrical framework in order to describe the multi-scale structure of a turbulent reactive front in the vicinity of a wall. The first part of the paper consists of a theoretical presentation; the second part represents an experimental illustration and verification. There are very few studies concerning the multi-scale structure of a turbulent front in the vicinity of a wall. Let us quote the work by Nicolleau [1] dealing with the dispersion, by a turbulent field, of a passive scalar near a wall. Fractal dimension has been shown to be dependent on the wall distance. Recently, Foucher et al. [2,3] performed a multi-scale analysis of turbulent flames, looking for the influence of the wall on the multiscale features. They also found that the fractal dimension depends on the wall distance. Even far from the wall, the exact multi-scale structure of a turbulent flame and, more generally of a turbulent interface, is still an open problem. Let us recall that, to define a fractal dimension $\Delta_{\mathrm{F}}$, one should have a scale-range large "enough" where the number $N\left[\mathrm{l}_{\mathrm{i}}\right]$ of balls of size $\mathrm{l}_{\mathrm{i}}$ needed to cover the front ("box-counting method") follows a power law, such as $N\left[\mathrm{l}_{\mathrm{i}}\right] \sim \mathrm{l}_{\mathrm{i}}^{-\Delta_{\mathrm{F}}}$. Nevertheless, the slope is usually determined over a limited scale-range (often less than one decade and for large scales, close to the integral scale). Moreover, it finally appeared that, the fractal dimension of turbulent fronts (passive or reactive) is paradoxically scale dependent [4-6]. Such a quite general behaviour calls for a more general description of multi-scale systems than pure scale

\footnotetext{
* Corresponding author. Tel.: +33145523531.

E-mail address: diogo.queiros-conde@ensta.fr (D. Queiros-Conde).
} 
invariance, and for a reinterpretation of the measured fractal dimension $\Delta_{\mathrm{F}}$. That is why the concept of scale-entropy has been introduced in the context of entropic-skins theory [7]. Recently, it has been shown that this framework can be used to derive the turbulent velocity of a flame as a function of ratio $\mathrm{U}^{\prime} / \mathrm{U}_{\mathrm{L}}[8]$.

Our paper has the ambition to propose a new geometrical framework, in order to clarify and to describe two main aspects of the multi-scale features of a turbulent flame near a wall: the scale-dependency of the fractal dimension and its dependency on the wall distance. Our work is based on the fundamental idea that a complex phenomenon, such as turbulent combustion can be described by a specific and dynamical scale construction. Such an idea is also developed in constructal theory [9] and leads to a powerful method to determine optimized multiscale configurations in a wide variety of physical systems. In the context of entropic-skins geometry, introducing the concept of scale-entropy and scale-evolutivity, we will propose a diffusion equation for scale-entropy which describes the multi-scale features of a flame as a function of scale and of wall distance.

\section{Characteristic scales: The scale-space and the wall-distance space}

First of all, let us introduce the characteristic scales involved in the double interaction of a flame with turbulence and with a wall and let us give their order of magnitude. A flame displays a thickness $\delta$, which constitutes the place where the combustion occurs. It mainly depends on the mixture. In the so-called "flamelet regime", the length-scales and the time-scales of turbulence are larger than the flame thickness and the chemical time. The front is just wrinkled and it is not internally modified. The turbulent flow, following Kolmogorov's theory [10], can be characterised by a hierarchy of vortices, ranging from the integral scale $l_{0}$ to Kolmogorov scale $\eta$. The turbulence-flame interaction is characterised by a hierarchy of length-scales wrinkling the flame. We define the inner cut-off scale $l_{c}$ as the smallest size of wrinkling produced on the front and the outer cut-off $\mathrm{l}_{\mathrm{M}}$ as the largest size of wrinkle, beyond which, the front is Euclidean. It has been shown that a good order of the magnitude of the internal cut-off scale corresponds to twice a Kolmogorov scale, calculated for burnt gases [6, 8]: $1_{\mathrm{C}}=2 \eta_{\mathrm{BG}}$ with $\eta_{\mathrm{BG}}=\left(\nu_{\mathrm{BG}}^{3} / \varepsilon\right)^{1 / 4}$ where $\varepsilon=U^{\prime 3} / 1_{0}$ represents the rate of energy dissipation of turbulence and $\nu_{\mathrm{BG}}$ the kinematic viscosity of burnt gases. Its order of magnitude is in our experiment $\mathrm{l}_{\mathrm{c}} \approx 0.2 \mathrm{~mm}$. The outer cut-off scale depends on the global configuration, and, mainly, the size of the front [2]: we obtained experimentally $l_{\mathrm{M}} \approx 11 \mathrm{~mm}$. The wrinkling on the flame results from two sorts of scales. The first scale-range is due to turbulence itself, whose integral scale is noted $1_{0}$ and the Kolmogorov scale $\eta$ : in our experiment, we have $\mathrm{l}_{0} \approx 2 \mathrm{~mm}$ and $\eta \approx 15 \mu \mathrm{m}$. The second scale-range comes from the large scale motions of the flow which is mainly due to cyclic fluctuations. Finally, the flame interacting with the wall leads to the quenching scale $d_{c}$ that is the distance below which the flame quenches when it approaches the wall. This scale results mainly from the heat losses at the wall but, in a turbulent configuration, it is linked to the wall-turbulence-flame interaction in a complex way. In the experiments used for this paper, its order of magnitude is $\mathrm{d}_{\mathrm{c}} \approx 0.1 \mathrm{~mm}$.

We will thus work here with two kinds of length scales. (i) The first one is the scale of a wrinkle created on the front by turbulent flow. This scale noted $l_{i}$ belongs to the range $\left[l_{c} ; l_{0}\right]$; (ii) The second kind of scale is the mean wall distance denoted $\mathrm{d}_{\mathrm{d}}$, where the flame is located with the assumption that one can define a mean wall distance. Working on the influence of the wall-distance relative to the scale-range $\left[l_{c} ; l_{0}\right]$, we are especially interested by values of wall-distance belonging to the wall-distance range $\left[l_{c} ; l_{0}\right]$. The first kind of scale will be said to belong to scale-space, and the second one to the walldistance space.

\section{Roughness, occupation volume, and scale-entropy of a turbulent flame}

To facilitate the reading of this paper, it is useful to present the main geometrical quantities we will use. Let us consider a turbulent flame wrinkled over a scale range $\left[l_{c} ; l_{0}\right]$. We will define here, the main geometrical quantities needed for our study. Let us consider a varying scale $l_{i}$ in this scale-range. In order to define the spatial extension of the flame at this scale, we define, in the spirit of box-counting method, $\mathrm{N}_{\mathrm{i}, 0}$ as the minimum number of balls necessary to cover the front contained in a scale $l_{0}$. Using this quantity, it is possible to define the turbulent surface due to the scale range $\left[\mathrm{l}_{\mathrm{i}} ; \mathrm{l}_{0}\right]$ by $\mathrm{S}_{\mathrm{T}}\left[\mathrm{l}_{\mathrm{i}} ; \mathrm{l}_{0}\right]=\mathrm{N}\left[\mathrm{l}_{\mathrm{i}} ; \mathrm{l}_{0}\right] \mathrm{l}_{\mathrm{i}}^{2}$ which implies a roughness

$$
\Sigma\left[\mathrm{l}_{\mathrm{i}} ; \mathrm{l}_{0}\right]=\mathrm{S}_{\mathrm{T}}\left[\mathrm{l}_{\mathrm{i}} ; \mathrm{l}_{0}\right] / \mathrm{l}_{0}^{2}=\mathrm{N}\left[\mathrm{l}_{\mathrm{i}} ; \mathrm{l}_{0}\right]\left(\mathrm{l}_{\mathrm{i}} / \mathrm{l}_{0}\right)^{2} .
$$

The volume occupied by the front at the scale $\mathrm{l}_{\mathrm{i}}$ is thus $\mathrm{V}\left[\mathrm{l}_{\mathrm{i}} ; \mathrm{l}_{0}\right]=\mathrm{N}\left[\mathrm{l}_{\mathrm{i}} ; \mathrm{l}_{0}\right] \mathrm{l}_{\mathrm{i}}^{\mathrm{dE}}$, where $\mathrm{d}_{\mathrm{E}}$ is the embedding dimension with here $d_{E}=3$. This set can be defined by its volume fraction $f\left[l_{i} ; l_{0}\right]=V\left[1_{i} ; l_{0}\right] / l_{0}^{3}$ or by the number $W\left[1_{i} ; l_{0}\right]=1 / f\left[1_{i} ; l_{0}\right]$ of sets needed to fill the whole volume. In this paper, we will thus use the scale-entropy defined by

$$
\mathrm{S}\left[\mathrm{l}_{\mathrm{i}} ; \mathrm{l}_{0}\right]=\ln \left(\mathrm{W}\left[\mathrm{l}_{\mathrm{i}} ; \mathrm{l}_{0}\right]\right) \quad \text { with } \mathrm{W}\left[\mathrm{l}_{\mathrm{i}} ; \mathrm{l}_{0}\right]=\mathrm{l}_{0}^{3} / \mathrm{V}\left[\mathrm{l}_{\mathrm{i}} ; \mathrm{l}_{0}\right] \text {. }
$$

Using this quantity, we can express the roughness that results from the effect occurring on the front of the scales in $\left[\mathrm{l}_{\mathrm{c}} ; \mathrm{l}_{\mathrm{i}}\right]$. For this purpose, we determine the total roughness $\Sigma\left[\mathrm{l}_{\mathrm{c}} ; \mathrm{l}_{0}\right]=\mathrm{S}_{\mathrm{T}}\left[\mathrm{l}_{\mathrm{c}} ; \mathrm{l}_{0}\right] / \mathrm{l}_{0}^{2}=\mathrm{N}\left[\mathrm{l}_{\mathrm{c}} ; \mathrm{l}_{0}\right]\left(\mathrm{l}_{\mathrm{c}} / \mathrm{l}_{0}\right)^{2}$. Using the property of roughness multiplicativity $\Sigma\left[\mathrm{l}_{c} ; \mathrm{l}_{\mathrm{i}}\right] \Sigma\left[\mathrm{l}_{\mathrm{i}} ; \mathrm{l}_{0}\right]=\Sigma\left[\mathrm{l}_{c} ; \mathrm{l}_{0}\right]$, we can deduce $\Sigma\left[\mathrm{l}_{c} ; \mathrm{l}_{\mathrm{i}}\right]$ from $\Sigma\left[\mathrm{l}_{\mathrm{i}} ; \mathrm{l}_{0}\right]$ through the measurement of $\mathrm{N}\left[\mathrm{l}_{\mathrm{i}} ; \mathrm{l}_{0}\right]$. Roughness and scale-entropy are simply linked by the following expression:

$$
\mathrm{S}\left[\mathrm{l}_{\mathrm{i}} ; \mathrm{l}_{0}\right]+\ln \left(\Sigma\left[\mathrm{l}_{\mathrm{i}} ; \mathrm{l}_{0}\right]\right)=\ln \left(\mathrm{l}_{0} / \mathrm{l}_{\mathrm{i}}\right) .
$$




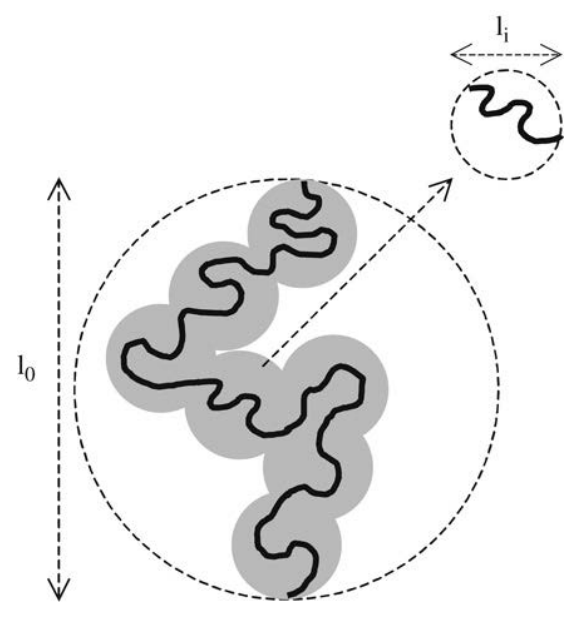

Fig. 1. Two ways to measure to measure the mean roughness $\Sigma\left[l_{c} ; l_{i}\right]$ of a front in a ball of size $l_{i}$. (i) The front is covered by the minimum number $N\left[l_{i} ; l_{0}\right]$ of balls (box-counting method) of size $\mathrm{l}_{\mathrm{i}}$ needed to cover the domain of global size $\mathrm{l}_{0} ;$ this leads to the roughness $\Sigma\left[\mathrm{l}_{\mathrm{i}} ; \mathrm{l}_{0}\right]=\mathrm{N}\left[\mathrm{l}_{\mathrm{i}} ; \mathrm{l}_{0}\right]\left(\mathrm{l}_{\mathrm{i}} / \mathrm{l}_{0}\right)^{2}$ due to the scale-range $\left[l_{i} ; l_{0}\right]$. Due to multiplicativity of roughness, we have $\Sigma\left[l_{c} ; 1_{i}\right]=\Sigma\left[l_{c} ; l_{0}\right] / \Sigma\left[l_{i} ; l_{0}\right]$. (ii) We take a particular ball in which the flame surface $s$ is computed, the local roughness is $\sigma\left[\mathrm{l}_{\mathrm{c}} ; \mathrm{l}_{\mathrm{i}}\right]=\mathrm{s} / \mathrm{l}_{\mathrm{i}}^{2}$. This local roughness vary along the front, and can be used to study roughness fluctuations. To have the mean roughness $\Sigma\left[1_{\mathrm{c}} ; \mathrm{l}_{\mathrm{i}}\right]$, an average is done over all the balls: $\left\langle\sigma\left[\mathrm{l}_{\mathrm{c}} ; \mathrm{l}_{\mathrm{i}}\right]\right\rangle=\Sigma\left[\mathrm{l}_{\mathrm{c}} ; \mathrm{l}_{\mathrm{i}}\right]$.

In order to facilitate the presentation of the experimental results in the second part of the paper, let us make three remarks.

(i) The box-counting method based on the measurement of $\mathrm{N}\left[\mathrm{l}_{\mathrm{i}} ; \mathrm{l}_{0}\right]$ (leading to $\mathrm{N}\left[\mathrm{l}_{\mathrm{c}} ; \mathrm{l}_{\mathrm{i}}\right]$ using roughness multiplicativity) gives access to a mean roughness $\Sigma\left[\mathrm{l}_{c} ; \mathrm{l}_{\mathrm{i}}\right]$ but, due to some experimental constraints, one needs to define a local roughness over the front (Fig. 1). In a ball of size $l_{i}$, if $s$ represents the surface of the front in this ball, then $\sigma\left[l_{c} ; l_{i}\right]=s / l_{i}^{2}$ is the local roughness in the ball of size $l_{i}$. Averaging this local quantity over the front (i.e. calculating an average on all the balls of size $l_{i}$ which are necessary to cover the front), allows one to recover the mean roughness, we have: $\Sigma\left[l_{c} ; l_{i}\right]=\left\langle\sigma\left[l_{c} ; l_{i}\right]\right\rangle$. Two methods can thus be used to measure roughness: the first, given by "box-counting method", has a global character in the sense that it directly provides a mean roughness; the second is "local", since it first consists of measuring the roughness locally and then to average it over the front, to obtain the mean roughness. This method is particularly interesting if one wants to characterize and study roughness fluctuations. There is a direct link between the roughness $\left\langle\sigma\left[\mathrm{l}_{c} ; \mathrm{l}_{\mathrm{i}}\right]\right\rangle\left(=\Sigma\left[\mathrm{l}_{c} ; \mathrm{l}_{\mathrm{i}}\right]\right)$ measured by the local method, and the one measured by the box-counting method $\Sigma\left[1_{i} ; 1_{0}\right]$. Due to the multiplicativity property of roughness, we have the expression $\Sigma\left[\mathrm{l}_{c} ; \mathrm{l}_{\mathrm{i}}\right] \Sigma\left[\mathrm{l}_{\mathrm{i}} ; \mathrm{l}_{0}\right]=\Sigma\left[\mathrm{l}_{c} ; \mathrm{l}_{0}\right]$. Hence, $1 / \Sigma\left[\mathrm{l}_{c} ; \mathrm{l}_{\mathrm{i}}\right]=\left(1 / \Sigma\left[\mathrm{l}_{c} ; \mathrm{l}_{0}\right]\right) \mathrm{N}\left[\mathrm{l}_{\mathrm{i}} ; \mathrm{l}_{0}\right]\left(\mathrm{l}_{\mathrm{i}} / \mathrm{l}_{0}\right)^{2}$. Measuring $\Sigma\left[\mathrm{l}_{\mathrm{c}} ; \mathrm{l}_{\mathrm{i}}\right]$ and representing $1 / \Sigma\left[\mathrm{l}_{\mathrm{c}} ; \mathrm{l}_{\mathrm{i}}\right]$ gives access to the quantity $\mathrm{N}\left[\mathrm{l}_{\mathrm{i}} ; \mathrm{l}_{0}\right]$ usually measured by box-counting method. In the specific case of fractality i.e. $N\left[1_{i} ; 1_{0}\right] \sim 1_{i}^{-\Delta_{F}}$ we thus have $1 / \Sigma\left[1_{i} ; l_{0}\right] \sim 1_{i}^{2-\Delta_{F}}$.

(ii) The experimental data are, in fact, composed by two-dimensional photographies of flames obtained by tomography images using Planar-Laser-Induced-Fluorescence. We thus need to define a linear roughness. If $\mathrm{N}_{2 \mathrm{D}}\left[\mathrm{l}_{\mathrm{i}} ; \mathrm{l}_{0}\right]$ is the number of disks of diameter $\mathrm{l}_{\mathrm{i}}$ needed to cover the front, the linear roughness is $\Lambda\left[\mathrm{l}_{\mathrm{i}} ; \mathrm{l}_{0}\right]=\mathrm{L}_{\mathrm{T}}\left[\mathrm{l}_{\mathrm{i}} ; \mathrm{l}_{0}\right] / \mathrm{l}_{0}=\mathrm{N}_{2 \mathrm{D}}\left[\mathrm{l}_{\mathrm{i}} ; \mathrm{l}_{0}\right]\left(\mathrm{l}_{\mathrm{i}} / \mathrm{l}_{0}\right)$ where $\mathrm{L}_{\mathrm{T}}\left[\mathrm{l}_{\mathrm{i}} ; \mathrm{l}_{0}\right]$ represents the length of the two-dimensional turbulent flame. As explained previously, for surface roughness, apart from the box-counting method, it is possible to measure the roughness by a second way. We can also determine roughness by measuring it locally on a ball of size $l_{i}$ which gives a local quantity $\lambda\left[l_{c} ; l_{i}\right]$; averaging over the front leads to the mean linear roughness $\Lambda\left[1_{c} ; 1_{i}\right]=\left\langle\lambda\left[1_{c} ; l_{i}\right]\right\rangle$ with the relation:

$$
1 / \Lambda\left[1_{c} ; l_{i}\right]=\left(1 / \Lambda\left[1_{c} ; l_{0}\right]\right) N_{2 D}\left[l_{i} ; l_{0}\right]\left(l_{i} / l_{0}\right) .
$$

For the specific case of a fractal object, we have $1 / \Lambda\left[1_{c} ; l_{i}\right] \sim 1_{i}^{1-\Delta_{F}, 2 D}$, where $\Delta_{F, 2 D}$ is the fractal dimension measured in a two-dimensional space. Assuming that the front is homogeneous and isotropic in the zone of its brush, we assume here that the two-dimensional cut of a tridimensional flame displays the same statistical and multi-scale properties leading to $\Delta_{\mathrm{F}}=1+\Delta_{\mathrm{F}, 2 \mathrm{D}}$. We can therefore study $\Lambda\left[\mathrm{l}_{\mathrm{c}} ; \mathrm{l}_{\mathrm{i}}\right]$, instead of $\Sigma\left[\mathrm{l}_{\mathrm{c}} ; \mathrm{l}_{\mathrm{i}}\right]$ to obtain the multi-scale features of the front.

(iii) To determine the distance to the wall of a flame, we must pay attention to the fact that the front is a multi-scale structure. If we consider the front at a scale $\mathrm{l}_{\mathrm{i}}$ (by covering by balls of size $\mathrm{l}_{\mathrm{i}}$ ), some parts of the front can be closer to the wall than others. The wall distance is not constant along the front, due to the fact that the front is multi-scale, but also due to the cyclic fluctuations which induces in the flow motions whose characteristic scale is larger than $1_{0}$. One way to avoid this experimental limitation, is to define a mean contour by a filtering on the front of the scales larger than the integral scale of turbulence. This is in agreement with the fact that our aim in this paper is to study the effect of turbulent scales on the flame i.e. which are scales smaller than integral scale. If we consider a ball of size $\mathrm{l}_{\mathrm{i}}$ on the front, the distance of this ball to the wall is given by the distance to the wall of the mean contour crossing the ball as it is shown in Fig. 2 . 


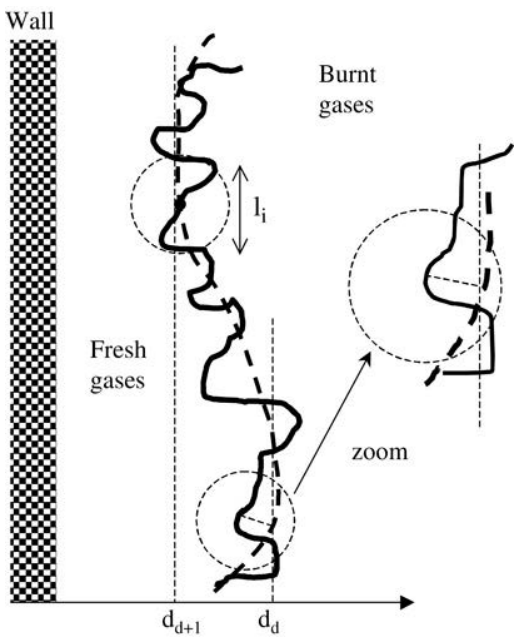

Fig. 2. The mean contour (bold dashed-line) is determined by filtering the scales larger than integral scale responsible of cyclic fluctuations. In each point of the instantaneous front, local roughness is measured in a disk of scale $\mathrm{l}_{\mathrm{i}}$ around the point. The wall-distance is measured from the point belonging to the mean contour, and obtained by drawing the perpendicular to the mean front to the wall.

\section{Scale-entropy flux and scale-evolutivity}

To study multi-scale features of flames near a wall, two cases must be considered. (i) The first one concerns the evolution, at a fixed wall distance, of a multi-scale structure when the scale varies. If the wall distance $d_{d}$ is larger than the integral scale of the flow $l_{0}$, the scale-range having a wrinkling effect on the flame is $\left[l_{c} ; l_{0}\right]$. If the wall distance $d_{d}$ is smaller than $l_{0}$, the scale-range having an effect on the front is reduced to $\left[l_{c} ; d_{d}\right]$. (ii) The second case concerns the evolution of multi-scale structure when the wall distance varies, mainly when this wall-distance becomes smaller than the integral scale.

\subsection{Multi-scale structure in scale-space}

Flame far from the wall: $\mathrm{d}_{\mathrm{d}} \geq \mathrm{l}_{0}$

In a first stage, let us consider that the influence of the wall on the front can be neglected; we will thus consider flames far from the wall: $d_{d} \geq l_{0}$. We start from a turbulent flow having a turbulent intensity $U^{\prime}$, and an integral scale noted $l_{0}$. The scale-range characterising the turbulence is thus $\left[\eta ; l_{0}\right]$ where $\eta$ represents the Kolmogorov length-scale. Let us consider a turbulent flame wrinkled by this flow. The scale-range over which the front is wrinkled is $\left[l_{c} ; l_{0}\right]$ where $l_{c}$ represents the internal cut-off scale. We assume, in this first case, that the turbulent flame is further to the wall than a distance equal to the integral scale i.e. $d_{d} \geq 1_{0}$. To simplify our presentation, we just consider a part of the flame defined by the scale $l_{0}$. The volume at integral scale is $l_{0}^{3}$. Let us now consider the flame at the scale $l_{\mathrm{i}}$ belonging to $\left[l_{c} ; l_{0}\right]$.

For each scale noted $\mathrm{l}_{\mathrm{i}}$ belonging to $\left[\mathrm{l}_{\mathrm{c}} ; \mathrm{l}_{0}\right]$ we define the associated occupation volume as $\mathrm{V}\left[\mathrm{l}_{\mathrm{i}} ; \mathrm{l}_{0}\right]$. If $\mathrm{N}\left[\mathrm{l}_{\mathrm{i}} ; \mathrm{l}_{0}\right]$ is the minimum number of balls of size $\mathrm{l}_{\mathrm{i}}$ needed to cover the flame, then $\mathrm{V}\left[\mathrm{l}_{\mathrm{i}} ; \mathrm{l}_{0}\right]=\mathrm{N}\left[\mathrm{l}_{\mathrm{i}} ; \mathrm{l}_{0}\right] \mathrm{l}_{\mathrm{i}}^{3}$. Since $\mathrm{N}\left[\mathrm{l}_{0} ; \mathrm{l}_{0}\right]=1$ we have $\mathrm{V}\left[\mathrm{l}_{0} ; \mathrm{l}_{0}\right]=\mathrm{l}_{0}^{3}$. We then define the ratio $\mathrm{V}\left[\mathrm{l}_{0} ; 1_{0}\right] / \mathrm{V}\left[\mathrm{l}_{\mathrm{i}} ; \mathrm{l}_{0}\right]$ which quantifies the number of occupation volumes $\mathrm{V}\left[\mathrm{l}_{\mathrm{i}} ; \mathrm{l}_{0}\right]$ associated to $l_{i}$ needed to fill the integral volume $V\left[1_{0} ; l_{0}\right]$. The scale-entropy $S\left[l_{i} ; l_{0}\right]$ corresponding to the scale-range $\left[l_{i} ; l_{0}\right]$ is defined by taking the logarithm of this quantity:

$$
\mathrm{S}\left[\mathrm{l}_{\mathrm{i}} ; \mathrm{l}_{0}\right]=\ln \left(\mathrm{V}\left[\mathrm{l}_{0} ; \mathrm{l}_{0}\right] / \mathrm{V}\left[\mathrm{l}_{\mathrm{i}} ; \mathrm{l}_{0}\right]\right) \text {. }
$$

A very particular case corresponds to a flame having a fractal structure in the scale-range $\left[\mathrm{l}_{\mathrm{i}} ; \mathrm{l}_{0}\right]$. In this case, $\mathrm{N}\left[\mathrm{l}_{\mathrm{i}} ; \mathrm{l}_{0}\right] \sim$ $\mathrm{l}_{\mathrm{i}}^{-\Delta_{\mathrm{F}}}$ where $\Delta_{\mathrm{F}}$ is the fractal dimension. It leads to the simple formula $S\left[\mathrm{l}_{\mathrm{i}} ; 1_{0}\right]=\left(3-\Delta_{\mathrm{F}}\right) \ln \left(\mathrm{l}_{0} / \mathrm{l}_{\mathrm{i}}\right)$. Let us remark that the scale-entropy $S\left[l_{i} ; l_{0}\right]$ is defined here by taking the largest scale $l_{0}$ as a reference. This means that when the scale $l_{i}$ approaches $l_{0}$, the scale-entropy tends to be null. It is maximum for the scale $l_{c}$. We can however define a scale-entropy relatively to the smallest scale by $S\left[1_{c} ; 1_{i}\right]=\ln \left(V\left[1_{i} ; 1_{i}\right] / V\left[1_{c} ; 1_{0}\right]\right)$ with $S\left[1_{c} ; 1_{i}\right]+S\left[1_{i} ; l_{0}\right]=\ln \left(1_{0}^{3} / V\left[1_{c} ; l_{0}\right]\right)$. The scale-entropy $S\left[1_{c} ; 1_{i}\right]$ follows a behaviour opposite to that of $S\left[l_{i} ; l_{0}\right]$ : it is null for the minimum scale $l_{c}$ and maximum at the integral scale. In this paper, we choose to work with a scale-entropy $S\left[1_{i} ; l_{0}\right]$ i.e. defined relative to the largest scale.

Let us now consider two scales $l_{i}$ and $l_{i+1}$ (with $l_{i+1}<l_{i}$ ), which are close enough to assume that the front is fractal in this elementary scale-range $\left[1_{i+1} ; 1_{i}\right]$, the "local" fractal dimension being $\Delta\left[1_{i}\right]$. It must be emphasised that this dimension is "local" in the scale-space in the sense that it characterises a fractality but in a very small scale-range. Of course, this local dimension is considered to be dependent on the scale $\mathrm{l}_{\mathrm{i}}$ : it is scale-dependent. The scale-entropy can be defined for $\mathrm{l}_{\mathrm{i}}$ and $l_{i+1}$. We are then interested on the scale-entropy jump between $l_{i+1}$ and $l_{i}$ noted:

$$
\mathrm{S}\left[\mathrm{l}_{\mathrm{i}} ; \mathrm{l}_{0}\right]-\mathrm{S}\left[\mathrm{l}_{\mathrm{i}+1} ; 1_{0}\right]=\ln \left(\mathrm{V}\left[\mathrm{1}_{\mathrm{i}+1} ; \mathrm{l}_{0}\right] / \mathrm{V}\left[\mathrm{I}_{\mathrm{i}} ; \mathrm{l}_{0}\right]\right)
$$


and the scale-entropy flux $\phi_{\mathrm{i}}$ by:

$$
\phi\left[1_{\mathrm{i}}\right]=\frac{\mathrm{S}\left[\mathrm{l}_{\mathrm{i}} ; \mathrm{l}_{0}\right]-\mathrm{S}\left[\mathrm{l}_{\mathrm{i}+1} ; \mathrm{l}_{0}\right]}{\ln \left(\mathrm{l}_{\mathrm{i}} / \mathrm{l}_{\mathrm{c}}\right)-\ln \left(\mathrm{l}_{\mathrm{i}+1} / \mathrm{l}_{\mathrm{c}}\right)} .
$$

Let us remark that, due to our definition of the scale-entropy, we have $S\left[1_{i} ; 1_{0}\right]-S\left[1_{i+1} ; 1_{0}\right]=-S\left[1_{i+1} ; 1_{i}\right]$ since $\mathrm{N}\left[\mathrm{l}_{\mathrm{i}+1} ; \mathrm{l}_{0}\right] / \mathrm{N}\left[\mathrm{l}_{\mathrm{i}} ; \mathrm{l}_{0}\right]=\mathrm{N}\left[\mathrm{l}_{\mathrm{i}+1} ; \mathrm{l}_{\mathrm{i}}\right]$. We thus obtain $\phi\left[\mathrm{l}_{\mathrm{i}}\right]=-\mathrm{S}\left[\mathrm{l}_{\mathrm{i}+1} ; \mathrm{l}_{\mathrm{i}}\right] / \ln \left(\mathrm{l}_{\mathrm{i}} / \mathrm{l}_{\mathrm{i}+1}\right)$. The scale-entropy flux can be easily calculated; for scales belonging to the elementary scale-range $\left[\mathrm{l}_{\mathrm{i}+1} ; \mathrm{l}_{\mathrm{i}}\right]$, we have $\mathrm{N}\left[\mathrm{l}_{\mathrm{i}+1} ; \mathrm{l}_{\mathrm{i}}\right] \sim 1^{-\Delta\left[\mathrm{l}_{\mathrm{i}}\right]}$; it gives:

$$
\phi\left[\mathrm{l}_{\mathrm{i}}\right]=\Delta\left[\mathrm{l}_{\mathrm{i}}\right]-\mathrm{d}_{\mathrm{E}} \quad\left(\text { with } \mathrm{d}_{\mathrm{E}}=3\right) .
$$

The scale-entropy flux in the scale-space is a negative local quantity. It expresses the idea that scale-entropy $S\left[1_{\mathrm{i}} ; \mathrm{l}_{0}\right]=$ $\ln \left(1_{0}^{3} / \mathrm{V}\left[\mathrm{l}_{\mathrm{i}} ; \mathrm{l}_{0}\right]\right)$ is a decreasing quantity when the scale is increasing. If the system is purely fractal, the flux $\phi\left[\mathrm{l}_{\mathrm{i}}\right]$ is a constant quantity since $\Delta\left[\mathrm{l}_{\mathrm{i}}\right]$ is a constant in the scale-range. But we now know that the local fractal dimension $\Delta\left[\mathrm{l}_{\mathrm{i}}\right]$ can vary with scale and thus leads to a variation of the scale-entropy flux. The absolute value of the flux $|\phi|_{\max }=\left|\phi\left[1_{\mathrm{C}}\right]\right|=\mathrm{d}_{\mathrm{E}}-\Delta\left[\mathrm{l}_{\mathrm{c}}\right]$ is a maximum for the inner cut-off scale $l_{c}$ corresponding to a local fractal dimension $\Delta\left[l_{c}\right]=2$ since the flame is without roughness at this scale. Its minimum $|\phi|_{\min }=\left|\phi\left[\mathrm{l}_{0}\right]\right|=\mathrm{d}_{\mathrm{E}}-\Delta\left[\mathrm{l}_{0}\right]$ is obtained at the integral scale $\mathrm{l}_{0}$ where the local fractal dimension is noted $\Delta\left[\mathrm{l}_{0}\right]$.

In order to characterise the deviation from scale-invariance in the elementary scale-range $\left[1_{i+1} ; 1_{i}\right]$, we propose to work with the difference $\phi\left[\mathrm{l}_{\mathrm{i}}\right]-\phi\left[\mathrm{l}_{\mathrm{i}+1}\right]=\Delta\left[\mathrm{l}_{\mathrm{i}}\right]-\Delta\left[\mathrm{l}_{\mathrm{i}+1}\right]$ and to introduce a quantity called scale-evolutivity $\omega\left[\mathrm{l}_{\mathrm{i}+1} ; \mathrm{l}_{\mathrm{i}}\right]$ such as $\phi\left[\mathrm{l}_{\mathrm{i}}\right]-\phi\left[\mathrm{l}_{\mathrm{i}+1}\right]=\omega\left[\mathrm{l}_{\mathrm{i}+1} ; \mathrm{l}_{\mathrm{i}}\right]\left[\ln \left(\mathrm{l}_{\mathrm{i}} / \mathrm{l}_{\mathrm{c}}\right)-\ln \left(\mathrm{l}_{\mathrm{i}+1} / \mathrm{l}_{\mathrm{c}}\right)\right]$. The specific fractal case corresponds to a scale evolutivity being null since the fractal dimension does not depend on the scale; we must have: $\omega\left[1_{i+1} ; l_{i}\right]=0$. The simplest behaviour after the fractal one is to consider the case of a constant scale-evolutivity, i.e. $\omega\left[1_{i+1} ; l_{i}\right]=\beta$ with $\beta>0$ in a scale range $\left[l_{j} ; l_{i}\right]$. This implies

$$
\omega\left[\mathrm{l}_{\mathrm{j}} ; \mathrm{l}_{\mathrm{i}}\right]=\frac{\phi\left[\mathrm{l}_{\mathrm{i}}\right]-\phi\left[\mathrm{l}_{\mathrm{j}}\right]}{\ln \left(\mathrm{l}_{\mathrm{i}} / \mathrm{l}_{\mathrm{c}}\right)-\ln \left(\mathrm{l}_{\mathrm{j}} / \mathrm{l}_{\mathrm{c}}\right)}=\frac{\Delta\left[\mathrm{l}_{\mathrm{i}}\right]-\Delta\left[\mathrm{l}_{\mathrm{j}}\right]}{\ln \left(\mathrm{l}_{\mathrm{i}} / \mathrm{l}_{\mathrm{c}}\right)-\ln \left(\mathrm{l}_{\mathrm{j}} / \mathrm{l}_{\mathrm{c}}\right)}=\beta .
$$

If scale-evolutivity is constant over the whole scale-range $\left[l_{c} ; l_{0}\right]$, the scale-evolutivity can then be written

$$
\omega\left[1_{c} ; 1_{0}\right]=\frac{\Delta\left[1_{0}\right]-\Delta\left[1_{c}\right]}{\ln \left(l_{0} / l_{c}\right)}=\beta .
$$

Since we know that $\Delta\left[\mathrm{l}_{\mathrm{c}}\right]=2$, in order to determine the numerical value of scale-evolutivity, we need to know the fractal dimension $\Delta\left[1_{0}\right]$, which should depend on the ratio $\mathrm{U}^{\prime} / \mathrm{U}_{\mathrm{L}}$. This is an occasion to clarify and reinterpret, in the context of our geometrical framework, what the fractal dimension $\Delta_{\mathrm{F}}$ measured in a wide variety of experimental configurations exactly represents. This dimension is, in fact, the slope taken for a limited scale-range $\left[1_{p} ; l_{0}\right]$ bounded by a large scale often close to the integral scale $\mathrm{l}_{0}$. The fractal dimension $\Delta_{\mathrm{F}}$ is, in fact, close to the local fractal dimension $\Delta\left[\mathrm{l}_{0}\right]$ : we will thus consider $\Delta\left[\mathrm{l}_{0}\right] \approx \Delta_{\mathrm{F}}$. For high values of $\mathrm{U}^{\prime} / \mathrm{U}_{\mathrm{L}}$, phenomenological arguments linked to Kolmogorov's spectrum lead to the prediction $\Delta_{\mathrm{F}}=7 / 3$ [11]. This value is derived by assuming that the characteristic velocity $\mathrm{u}_{\mathrm{i}}^{\prime}$ of a motion of scale $\mathrm{l}_{\mathrm{i}}$ follows $\mathrm{u}_{\mathrm{i}}^{\prime} \sim \mathrm{l}_{\mathrm{i}}^{\zeta_{1}}$ with $\zeta_{1}=1 / 3$. The argument leads to $\Delta_{\mathrm{F}}=2+\zeta_{1}$. The phenomenon of intermittency is not taken into account here. It has been shown that, for high Reynolds numbers, in the intermittent case, we rather have $\zeta_{1}=2 \gamma-1$ with $\gamma=\left((1+3 / \sqrt{8})^{1 / 3}+(1-3 / \sqrt{8})^{1 / 3}\right)^{3} \approx 0.68$ i.e. $\zeta_{1}=0.36$ which thus implies $\Delta_{F}=2.36$ [12]. The scaling $\zeta_{1}=0.36$ is in fact what is observed experimentally in a homogeneous and isotropic turbulence. This value $\Delta_{\mathrm{F}}=2.36$ gives support to the experimental result by Mantzaras et al. [13] showing that the fractal dimension tends towards the value 2.36 for $\mathrm{U}^{\prime} / \mathrm{U}_{\mathrm{L}}>4$. As an indication of the order of magnitude of $\beta$, if we take $\mathrm{l}_{\mathrm{c}}=0.2 \mathrm{~mm}, \mathrm{l}_{0}=2 \mathrm{~mm}, \Delta\left[\mathrm{l}_{\mathrm{c}}\right]=2$ and $\Delta_{\mathrm{F}}=7 / 3$, it leads to $\beta_{\max }=0.14$ and, with $\Delta_{\mathrm{F}}=2.36$, we have 0.156 . These values would correspond to high $\mathrm{U}^{\prime} / \mathrm{U}_{\mathrm{L}}$ ratios. We can be more precise, since $\Delta_{\mathrm{F}}$ depends on $\mathrm{U}^{\prime} / \mathrm{U}_{\mathrm{L}}$. In this frame, we need an expression that gives the fractal dimension as a function of the ratio $\mathrm{U}^{\prime} / \mathrm{U}_{\mathrm{L}}$ characterising the turbulence-combustion interaction. Let us quote the phenomenological expression obtained by North and Santavicca [14]: $\Delta_{\mathrm{F}, \mathrm{NS}}=\left[2.05 /\left(1+\mathrm{U}^{\prime} / \mathrm{U}_{\mathrm{L}}\right)\right]+\left[2.35 /\left(1+\mathrm{U}_{\mathrm{L}} / \mathrm{U}^{\prime}\right)\right]$. This expression has been established by considering two extremum values obtained experimentally: 2.05 for low $\mathrm{U}^{\prime} / \mathrm{U}_{\mathrm{L}}$ and 2.35 for high values (a value close to 2.36 obtained in the Refs. [12,13]). To be consistent with the fact that for $\mathrm{U}^{\prime} / \mathrm{U}_{\mathrm{L}} \rightarrow 0$, one should have $\Delta_{\mathrm{F}, \min }=2$ and that, for high values of $\mathrm{U}^{\prime} / \mathrm{U}_{\mathrm{L}}$, we rather have $\Delta_{\mathrm{F}, \max }=2.36$, we propose the slightly modified expression $\Delta_{\mathrm{F}}=\left[2 /\left(1+\mathrm{U}^{\prime} / \mathrm{U}_{\mathrm{L}}\right)\right]+\left[2.36 /\left(1+\mathrm{U}_{\mathrm{L}} / \mathrm{U}^{\prime}\right)\right]$, which numerically does imply a negligible change, but is more coherent with experimental and theoretical features. In our experimental conditions, since $\mathrm{U}^{\prime} / \mathrm{U}_{\mathrm{L}}=3.53$, it gives $\Delta_{\mathrm{F}}^{*}=\Delta\left[1_{0}\right]=2.28$ and thus a scale-evolutivity noted $\beta^{*}=0.122$.

Flame near the wall: $\mathrm{d}_{\mathrm{d}} \leq \mathrm{l}_{0}$

When the distance $d_{d}$ of the flame to the wall becomes smaller than the integral scale of the turbulence, the scales of the flow (in the direction perpendicularly to the wall) between the flame and the wall become smaller than the integral scale. The scale-range having an impact on the front is not $\left[l_{c} ; l_{0}\right]$ anymore but is reduced to $\left[l_{c} ; d_{d}\right]$. The wall-distance $d_{d}$ thus constrains the scale-range, and imposes a sort of new integral scale to the flow at this distance. All the definitions and equations written for the previous case $d_{d} \geq l_{0}$ can be conserved just by replacing $l_{0}$ by $d_{d}$. The new scale-entropy is $S\left[1_{i} ; d_{d}\right]=\ln \left(V\left[d_{d} ; d_{d}\right] / V\left[1_{i} ; d_{d}\right]\right)$; the scale-entropy jump is $S\left[1_{i} ; d_{d}\right]-S\left[1_{i+1} ; d_{d}\right]=\ln \left(V\left[l_{i} ; d_{d}\right] / V\left[1_{i+1} ; d_{d}\right]\right)$; the scaleentropy flux is unchanged and is defined by $\phi\left[\mathrm{l}_{\mathrm{i}}\right]=\left[\mathrm{S}\left[\mathrm{l}_{\mathrm{i}} ; \mathrm{d}_{\mathrm{d}}\right]-\mathrm{S}\left[\mathrm{l}_{\mathrm{i}+1} ; \mathrm{d}_{\mathrm{d}}\right]\right] /\left[\ln \left(\mathrm{l}_{\mathrm{i}} / \mathrm{l}_{\mathrm{c}}\right)-\ln \left(\mathrm{l}_{\mathrm{i}+1} / \mathrm{l}_{\mathrm{c}}\right)\right]=\Delta\left[\mathrm{l}_{\mathrm{i}}\right]-\mathrm{d}_{\mathrm{E}}$. 


\subsection{Evolution of multi-scale features with wall-distance}

In a second stage, we will consider the scale $\mathrm{l}_{\mathrm{i}}$ as a constant, and make the wall distance vary. To do so, in analogy with the scale-space, we define a hierarchy of wall-distance scales noted $d_{d}$ between $l_{c}$ and $l_{0}$. The scale-entropy is now defined by $S\left[l_{i} ; d_{d}\right]$, corresponding to the scale-range $\left[l_{i} ; d_{d}\right]$ is defined by

$$
\mathrm{S}\left[\mathrm{l}_{\mathrm{i}} ; \mathrm{d}_{\mathrm{d}}\right]=\ln \left(\mathrm{V}\left[\mathrm{d}_{\mathrm{d}} ; \mathrm{d}_{\mathrm{d}}\right] / \mathrm{V}\left[\mathrm{l}_{\mathrm{i}} ; \mathrm{d}_{\mathrm{d}}\right]\right) \text { with } \mathrm{V}\left[\mathrm{d}_{\mathrm{d}} ; \mathrm{d}_{\mathrm{d}}\right]=\mathrm{d}_{\mathrm{d}}^{3} \text {. }
$$

We then consider two close positions $d_{d}$ and $d_{d+1}$, of the front relative to the wall (with $d_{d+1}<d_{d}$ ); their respective scale entropies are $S\left[l_{i} ; d_{d}\right]$ and $S\left[l_{i} ; d_{d+1}\right]$. The scale-entropy jump is defined by $S\left[l_{i} ; d_{d}\right]-S\left[l_{i} ; d_{d+1}\right]$. Due to our definition of scale entropy, we have $S\left[\mathrm{l}_{i} ; \mathrm{d}_{\mathrm{d}}\right]-\mathrm{S}\left[\mathrm{l}_{\mathrm{i}} ; \mathrm{d}_{\mathrm{d}+1}\right]=\mathrm{S}\left[\mathrm{d}_{\mathrm{d}+1} ; \mathrm{d}_{\mathrm{d}}\right]$. It becomes possible to introduce a scale entropy flux through the wall-distance space.

$$
\psi\left[\mathrm{d}_{\mathrm{d}}\right]=\frac{\mathrm{S}\left[\mathrm{l}_{\mathrm{i}} ; \mathrm{d}_{\mathrm{d}}\right]-\mathrm{S}\left[\mathrm{l}_{\mathrm{i}} ; \mathrm{d}_{\mathrm{d}+1}\right]}{\ln \left(\mathrm{d}_{\mathrm{d}} / \mathrm{l}_{\mathrm{c}}\right)-\ln \left(\mathrm{d}_{\mathrm{d}+1} / \mathrm{l}_{\mathrm{c}}\right)}
$$

We have the relation $\psi\left[\mathrm{d}_{\mathrm{d}}\right]=\mathrm{S}\left[\mathrm{d}_{\mathrm{d}+1} ; \mathrm{d}_{\mathrm{d}}\right] / \ln \left(\mathrm{d}_{\mathrm{d}} / \mathrm{d}_{\mathrm{d}+1}\right)$. Using the fact that $\mathrm{N}\left[\mathrm{l}_{\mathrm{i}} ; \mathrm{d}_{\mathrm{d}}\right] / \mathrm{N}\left[\mathrm{l}_{\mathrm{i}} ; \mathrm{d}_{\mathrm{d}+1}\right]=\mathrm{N}\left[\mathrm{d}_{\mathrm{d}+1} ; \mathrm{d}_{\mathrm{d}}\right]$; we can easily express the scale-entropy flux, assuming that the front is locally fractal in the scale range $\left[\mathrm{d}_{\mathrm{d}+1} ; \mathrm{d}_{\mathrm{d}}\right]$ with a dimension $\Delta^{\psi}\left[\mathrm{d}_{\mathrm{d}}\right]$. The dimension $\Delta^{\psi}\left[\mathrm{d}_{\mathrm{d}}\right]$ is a local quantity: the symbol ' $\psi$ ' indicates that it concerns a variation of wall-distance. We insist that it does not mean that the front at the wall-distance $d_{d}$ is fractal (whose dimension would be $\Delta^{\psi}\left[d_{d}\right]$ ) over the whole scale range $\left[l_{c} ; d_{d}\right]$, but only that it is fractal in the elementary scale range $\left[d_{d+1} ; d_{d}\right]$. The scale-evolutive flux can then be calculated easily, since for scales 1 belonging to $\left[\mathrm{d}_{\mathrm{d}+1} ; \mathrm{d}_{\mathrm{d}}\right]$, we have $\mathrm{N}\left[\mathrm{d}_{\mathrm{d}+1} ; \mathrm{d}_{\mathrm{d}}\right] \sim \mathrm{l}^{-\Delta\left[\mathrm{d}_{\mathrm{d}}\right]}$. It leads to

$$
\psi\left[\mathrm{d}_{\mathrm{d}}\right]=\mathrm{d}_{\mathrm{E}}-\Delta^{\psi}\left[\mathrm{d}_{\mathrm{d}}\right] \quad\left(\text { with } \mathrm{d}_{\mathrm{E}}=3\right) \text {. }
$$

The wall scale-entropy flux is now a positive quantity, given the fact that when the wall-distance increases, wall-scaleentropy increases. It is maximal at a wall-distance equal to the inner cut-off scale and minimal at a wall-distance corresponding to the integral scale. Moreover, we have $\phi\left[\mathrm{l}_{\mathrm{i}}\right]+\psi\left[\mathrm{d}_{\mathrm{d}}\right]=\Delta\left[\mathrm{l}_{\mathrm{i}}\right]-\Delta^{\psi}\left[\mathrm{d}_{\mathrm{d}}\right]$. When the wall-distance is the same than the scale $\left(\mathrm{d}_{\mathrm{d}}=\mathrm{l}_{\mathrm{i}}\right)$, since we have $\phi\left[\mathrm{l}_{\mathrm{i}}\right]=-\mathrm{S}\left[\mathrm{l}_{\mathrm{i}+1} ; \mathrm{l}_{\mathrm{i}}\right] / \ln \left(\mathrm{l}_{\mathrm{i}} / \mathrm{l}_{\mathrm{i}+1}\right)$ and $\psi\left[\mathrm{d}_{\mathrm{d}}\right]=\mathrm{S}\left[\mathrm{d}_{\mathrm{d}+1} ; \mathrm{d}_{\mathrm{d}}\right] / \ln \left(\mathrm{d}_{\mathrm{d}} / \mathrm{d}_{\mathrm{d}+1}\right)$, it leads to $\phi\left[\mathrm{l}_{\mathrm{i}}\right]+\psi\left[\mathrm{l}_{\mathrm{i}}\right]=0$ and then $\Delta\left[\mathrm{l}_{\mathrm{i}}\right]=\Delta^{\psi}\left[\mathrm{l}_{\mathrm{i}}\right]$. We can write $\Delta^{\psi}\left[\mathrm{l}_{\mathrm{c}}\right]=\Delta\left[\mathrm{l}_{\mathrm{c}}\right]$ and $\Delta^{\psi}\left[\mathrm{l}_{0}\right]=\Delta\left[\mathrm{l}_{0}\right]$.

In analogy with the multi-scale structure in scale-space, we would like to characterise the deviation from pure scale invariance by introducing a scale-evolutivity $\varpi\left[d_{d+1} ; d_{d}\right]$ such as $\psi\left[d_{d}\right]-\psi\left[d_{d+1}\right]=\varpi\left[d_{d+1} ; d_{d}\right]\left[\ln \left(d_{d} / l_{c}\right)-\ln \left(d_{d+1} / l_{c}\right)\right]$. The fractal case corresponds to $\varpi\left[d_{d+1} ; d_{d}\right]=0$. Similarly, we consider the case $\varpi\left[d_{d+1} ; d_{d}\right]=\gamma$ as a constant. If the fractal dimension decreases when the flame approaches the wall $\left(\Delta\left[\mathrm{d}_{\mathrm{d}+1}\right]<\Delta\left[\mathrm{d}_{\mathrm{d}}\right]\right)$, then this case corresponds to $\varpi\left[\mathrm{d}_{\mathrm{d}}\right]=-\gamma$ with $\gamma>0$. In a scale-range $\left[\mathrm{d}_{\mathrm{j}} ; \mathrm{d}_{\mathrm{i}}\right]$, it gives

$$
\varpi\left[d_{j} ; d_{i}\right]=\frac{\psi\left[d_{i}\right]-\psi\left[d_{j}\right]}{\ln \left(d_{i} / l_{c}\right)-\ln \left(d_{j} / l_{c}\right)}=\frac{\Delta^{\psi}\left[d_{j}\right]-\Delta^{\psi}\left[d_{i}\right]}{\ln \left(d_{i} / l_{c}\right)-\ln \left(d_{j} / l_{c}\right)}=-\gamma .
$$

If scale-evolutivity is constant between $d_{d}=l_{c}$ and $d_{d}=l_{0}$, $i$.e. constant over the wall-distance range [ $1_{c}$; $1_{0}$ ], the scaleevolutivity can be written

$$
\varpi\left[1_{c} ; 1_{0}\right]=\frac{\Delta^{\psi}\left[1_{c}\right]-\Delta^{\psi}\left[1_{0}\right]}{\ln \left(1_{0} / 1_{c}\right)}=-\gamma
$$

Let us remark that, since $\Delta^{\psi}\left[1_{c}\right]=\Delta\left[1_{c}\right]$ and $\Delta^{\psi}\left[1_{0}\right]=\Delta\left[1_{0}\right]$, we have $\gamma=\beta$. So, if scale-evolutivity is constant in the whole scale-range and the whole range of wall-distances, this implies that scale-evolutivities are the equal in both ranges.

\section{Diffusion equation in scale-space: The specific case of parabolic scaling}

So far, we worked with discrete scales, with the aim of introducing the main concepts of our approach progressively and in a clear manner. We will now introduce continuous quantities, in order to define a continuous description. Let us note $\mathrm{x}=\ln \left(\mathrm{l}_{\mathrm{i}} / \mathrm{l}_{\mathrm{c}}\right)$. We consider here a flame whose mean distance to the wall $\left(\xi=\ln \left(\mathrm{d}_{\mathrm{d}} / \mathrm{l}_{\mathrm{c}}\right)\right.$ is fixed with $\left.\mathrm{x}<\xi\right)$; we are merely interested on the scale dependence of this flame, i.e. on the way in which it is built in terms of multi-scale structure.

We consider an elementary scale-range between $\mathrm{x}$ and $\mathrm{x}+\mathrm{dx}(\mathrm{dx}$ is here a differential) (Fig. 3). We assume that the front is locally fractal in the elementary scale range $[\mathrm{x} ; \mathrm{x}+\mathrm{dx}]$ with a dimension denoted $\Delta_{\mathrm{x}}$. The scale-entropy flux is $\phi_{\mathrm{x}}=\mathrm{dS}_{\mathrm{x}} / \mathrm{dx}=\Delta_{\mathrm{x}}-\mathrm{d}_{\mathrm{E}}$ where $\mathrm{d}_{\mathrm{E}}$ is the dimension of the embedding space, i.e. $\mathrm{d}_{\mathrm{E}}=3$, if we consider three-dimensional flames. We can also define the scale-entropy flux at scale $\mathrm{x}+\mathrm{dx}$; it leads to $\phi_{\mathrm{x}+\mathrm{dx}}=\Delta_{\mathrm{x}+\mathrm{dx}}-\mathrm{d}_{\mathrm{E}}$. For the specific case of an object which is fractal over a large "enough" scale-range, the fractal dimension is a constant, the scale-entropy flux is a constant and the local scale-evolutivity is zero over all the scale-range: $\omega(x)=\omega\left[l_{i+1} ; l_{i}\right]=0, \forall l_{i}$. In a general case, the local fractal dimension evolves in scale-space, the scale-evolutive flux is not a constant and the scale-evolutivity is not null. Hence, we assume that there is a production or a loss of scale entropy noted $\omega(\mathrm{x}) \mathrm{dx}$ such as $\phi_{\mathrm{x}+\mathrm{dx}}-\phi_{\mathrm{x}}=\omega(\mathrm{x}) \mathrm{dx}$. It leads to the equation

$$
\frac{\mathrm{d}^{2} S_{x}}{d x^{2}}-\omega(x)=0
$$


a

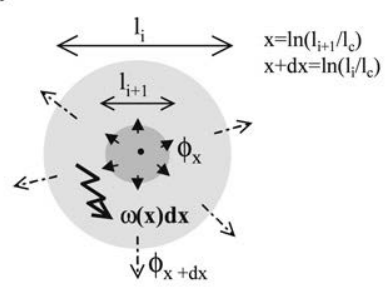

b

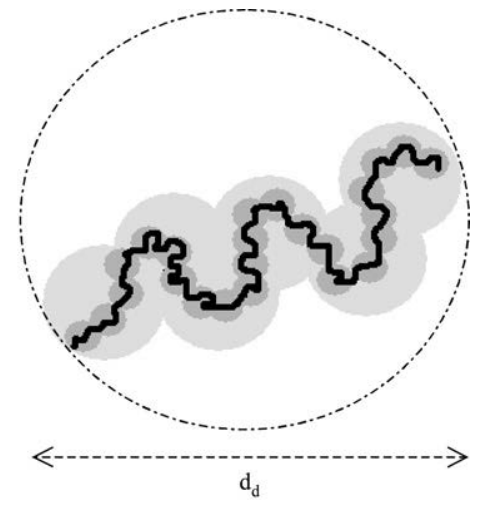

d

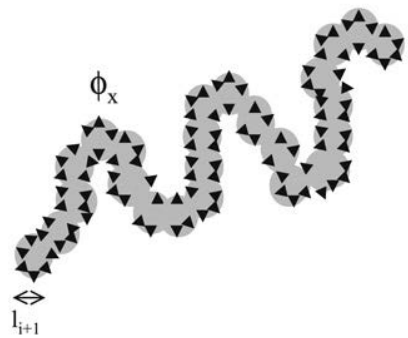

Fig. 3. (a) Sketch explaining scale-entropy diffusion equation between two consecutive scales $l_{i+1}$ et $l_{i}$. (b) Front contained in a domain of size $d_{d}$ covered by balls of size $l_{i+1}$ and then by balls of size $l_{i}(c)$ Volume of occupation corresponding to scale $l_{i}$ and its associated scale-entropy flux $\phi_{x}$. (d) Volume of occupation corresponding to scale $\mathrm{l}_{\mathrm{i}+1}$ and its associated scale-entropy flux $\phi_{\mathrm{x}+\mathrm{dx}}$.

This equation can be generalised, in order to take into account temporal variations of turbulence-flame interaction due to changes in the boundary conditions. This is possible, thanks to the concept of "scale-diffusivity" $\chi$ [7]. This concept characterises the capacity of a multi-scale system to propagate perturbations through scale-space. Nevertheless, in the frame of this paper, we will only consider the stationary regime. A very simple case, where local scale-evolutivity is a constant over scale-space, can be considered. This signifies an equipartition of scale-entropy production or losses. In other words, the scale-entropy flux sink is uniform over scale-space. This case has been linked to constructal theory in the study of a fluid distribution system [15]. It corresponds to $\omega(x)=\beta$ with $\beta>0$. We thus have the equation

$$
\frac{\mathrm{d}^{2} \mathrm{~S}_{\mathrm{x}}}{\mathrm{dx}^{2}}-\beta=0
$$

The boundary conditions are defined by

(i) $\phi_{\mathrm{x}=0}=\Delta\left[\mathrm{l}_{\mathrm{C}}\right]-\mathrm{d}_{\mathrm{E}} \quad$ with $\mathrm{d}_{\mathrm{E}}=3$;

(ii) $\phi_{\mathrm{x}=\mathrm{x}_{\mathrm{d}}=\ln \left(\mathrm{d}_{\mathrm{d}} / \mathrm{l}_{\mathrm{c}}\right)}=\Delta\left[\mathrm{d}_{\mathrm{d}}\right]-\mathrm{d}_{\mathrm{E}}$;

(iii) $S_{x=x_{d}=\ln \left(d_{d} / I_{c}\right)}=0$.

We can thus derive the expression of scale entropy where $x_{d}=\ln \left(d_{d} / l_{c}\right)$ (we have $\left.\xi<x_{d}\right)$ :

$$
\mathrm{S}_{\mathrm{x}}=(\beta / 2) \mathrm{x}^{2}+\left(\Delta\left[\mathrm{l}_{\mathrm{c}}\right]-\mathrm{d}_{\mathrm{E}}\right) \mathrm{x}-(\beta / 2) \mathrm{x}_{\mathrm{d}}^{2}-\left(\Delta\left[\mathrm{l}_{\mathrm{c}}\right]-\mathrm{d}_{\mathrm{E}}\right) \mathrm{x}_{\mathrm{d}} .
$$

Scale-entropy is thus a second-order polynomial of scale-logarithm: we propose to refer to this case by the expression "parabolic scaling". Scale-entropy can be written in the following forms:

$$
\begin{aligned}
& \mathrm{S}_{\mathrm{x}}=\left(\mathrm{x}-\mathrm{x}_{\mathrm{d}}\right)\left[\Delta\left[\mathrm{l}_{\mathrm{c}}\right]-\mathrm{d}_{\mathrm{E}}+\beta\left(\mathrm{x}+\mathrm{x}_{\mathrm{d}}\right) / 2\right] ; \\
& \mathrm{S}_{\mathrm{x}}=\ln \left[\left(\mathrm{d}_{\mathrm{d}} / \mathrm{l}_{\mathrm{i}}\right)^{\mathrm{d}_{\mathrm{E}}-\left(\Delta_{\mathrm{x}}+\Delta_{\mathrm{x}_{\mathrm{d}}}\right) / 2}\right] .
\end{aligned}
$$

Let us introduce a mean fractal dimension between $\mathrm{x}$ and $\mathrm{x}_{\mathrm{d}}$ by $\bar{\Delta}_{\mathrm{x}, \mathrm{x}_{\mathrm{d}}}=\left(\Delta_{\mathrm{x}}+\Delta_{\mathrm{x}_{\mathrm{d}}}\right) / 2$. We can write:

$$
\mathrm{S}_{\mathrm{x}}=\left(\mathrm{x}_{\mathrm{d}}-x\right)\left(\mathrm{d}_{\mathrm{E}}-\bar{\Delta}_{\mathrm{x}, \mathrm{x}_{\mathrm{d}}}\right) .
$$

It leads to a local fractal dimension, $\phi_{\mathrm{x}}=\mathrm{dS}_{\mathrm{x}} / \mathrm{dx}=\Delta_{\mathrm{x}}-\mathrm{d}_{\mathrm{E}}$, that varies linearly with the logarithmic scale coordinate $\mathrm{x}$ :

$$
\Delta_{\mathrm{x}}=\Delta\left[\mathrm{l}_{\mathrm{c}}\right]+\beta \mathrm{x} \text { with } \beta=\left(\Delta\left[\mathrm{l}_{0}\right]-\Delta\left[\mathrm{l}_{\mathrm{c}}\right]\right) / \ln \left(\mathrm{l}_{0} / \mathrm{l}_{\mathrm{c}}\right) .
$$


In the particular case of parabolic scaling, the evolution of $\ln N\left[l_{i} ; l_{0}\right]$ as a function of scale $x=\ln \left(l_{i} / l_{c}\right)$ leads to a parabolic form since

$$
\ln \mathrm{N}\left[\mathrm{l}_{\mathrm{i}} ; \mathrm{l}_{0}\right]=3\left(\mathrm{x}_{0}-\mathrm{x}\right)-\mathrm{S}_{\mathrm{x}}
$$

where $\mathrm{x}_{0}=\ln \left(\mathrm{l}_{0} / \mathrm{l}_{\mathrm{c}}\right)$. Experimentally, the curvature (departure from scale-invariance) can be observed, but only for large enough scale-range. As already expressed, for limited scale-ranges, due to experimental uncertainties, the curve can unfairly be taken as linear (having a slope $\Delta_{\mathrm{F}}$ ) as it has often been the case for the studies investigating the "fractal structure" of fronts: the scale analysis is approximated by a linear behaviour meaning a fractal behaviour. The pseudo-fractal dimension $\mathrm{D}_{\mathrm{f}, \mathrm{m}}$ measured for the scale range $\left[\mathrm{l}_{\mathrm{j}} ; \mathrm{l}_{\mathrm{i}}\right]$ corresponds in fact to the arithmetic mean fractal dimension between $\mathrm{l}_{\mathrm{j}}$ and $\mathrm{l}_{\mathrm{i}}: \mathrm{D}_{\mathrm{f}, \mathrm{m}}=\left(\Delta\left[\mathrm{l}_{\mathrm{j}}\right]+\Delta\left[\mathrm{l}_{\mathrm{i}}\right]\right) / 2$. More details about this point can be found in Ref. [7]. We have

$$
\ln N\left[1_{j} ; 1_{0}\right]-\ln N\left[1_{i} ; l_{0}\right]=\ln N\left[1_{j} ; l_{i}\right]=\left(l_{i} / l_{j}\right)^{D_{f, m}} .
$$

This property can be used to overcome a number of experimental difficulties, to measure a local fractal dimension $\Delta\left[\mathrm{l}_{\mathrm{i}}\right]$. If we can more easily measure a local fractal dimension $\Delta\left[l_{j}\right]$ for another scale $l_{j}$, measuring the mean dimension $D_{f, m}$ in the scale range $\left[\mathrm{l}_{\mathrm{j}} ; \mathrm{l}_{\mathrm{i}}\right]$ gives $\Delta\left[\mathrm{l}_{\mathrm{i}}\right]$ since $\Delta\left[\mathrm{l}_{\mathrm{i}}\right]=2 \mathrm{D}_{\mathrm{f}, \mathrm{m}}-\Delta\left[\mathrm{l}_{\mathrm{j}}\right]$.

\section{Diffusion equation in the wall-distance space: The specific case of parabolic scaling}

We consider two close positions of the flame relatively to the wall denoted $d_{d}$ and $d_{d+1}$ with $d_{d+1}<d_{d}$. An elementary jump in the wall-distance is thus defined by the transition from $\xi-d \xi=\ln \left(d_{d+1} / l_{c}\right)$ to $\xi=\ln \left(d_{d} / l_{c}\right)$. In this part, we will keep constant the scale defined by $\mathrm{x}=\ln \left(\mathrm{l}_{\mathrm{i}} / \mathrm{l}_{\mathrm{c}}\right)$. Let us emphasize that the variable $\xi$ is non-dimensionalised, by using the internal cut-off $l_{c}$ and not with the quenching scale $d_{c}$. Even if these two scales are very close in terms of the order of magnitude, $\left(l_{c}\right.$ is slightly larger than $\left.d_{c}: l_{c} \approx 2 d_{c}\right)$, the main reason is that, in a turbulent-flame interaction study, the scale of reference is the one with an effect on the front i.e. $1_{c}$. The scale-entropy $S\left[l_{i} ; d_{d}\right]=\ln \left(V\left[d_{d} ; d_{d}\right] / V\left[l_{i} ; d_{d}\right]\right)$ here is only dependent on wall-distance. By using continuous quantities and keeping the scale $l_{i}$ constant, we note $S_{\xi}$ as the corresponding scale-entropy. The scale-entropy flux is $\psi_{\xi}=\mathrm{d} S_{\xi} / \mathrm{d} \xi$. If, in this elementary scale-range, a local fractal behaviour is assumed with a dimension $\Delta^{\psi}[\xi]$, it can be easily shown that $\psi_{\xi}=\mathrm{d}_{\mathrm{E}}-\Delta^{\psi}[\xi]$. We then assume the existence of a conservation law for the scale-entropy flux: $\psi_{\xi+\mathrm{d} \xi}-\psi_{\xi}=\varpi(\xi) \mathrm{d} \xi$. We thus derive the following equation:

$$
\frac{\mathrm{d}^{2} S_{\xi}}{\mathrm{d} \xi^{2}}-\varpi(\xi)=0
$$

As in the case of the multi-scale structure in scale space, this equation can also be generalised, in order to take into account temporal variations with the concept of "scale-diffusivity" $\chi$ [7] but we will consider the stationary regime here. If the local scale-evolutivity is a constant over scale-space $\varpi(\xi)=-\gamma$ with $\gamma>0$. We thus have the equation

$$
\frac{\mathrm{d}^{2} S_{\xi}}{\mathrm{d} \xi^{2}}+\gamma=0
$$

The boundary conditions are defined by

$$
\begin{aligned}
& \text { (i) } \phi_{\xi=0}=\mathrm{d}_{\mathrm{E}}-\Delta\left[\mathrm{l}_{\mathrm{c}}\right] \text {; } \\
& \text { (ii) } \phi_{\xi=\xi_{\mathrm{i}}=\ln \left(\mathrm{l}_{\mathrm{i}} / \mathrm{l}_{\mathrm{C}}\right)}=\mathrm{d}_{\mathrm{E}}-\Delta\left[\mathrm{l}_{\mathrm{i}}\right]=\mathrm{d}_{\mathrm{E}}-\Delta_{\mathrm{x}} \text {; } \\
& \text { (iii) } S_{\xi}=\xi_{i}=\ln \left(l_{i} / l_{c}\right)=0 \text {. }
\end{aligned}
$$

We thus can derive the expression of scale entropy where $\xi_{i}=\ln \left(l_{i} / l_{c}\right)\left(\right.$ with $\left.\xi_{i}<\xi\right)$. It gives:

$$
\begin{aligned}
& S_{\xi}=-(\gamma / 2) \xi^{2}+\left(d_{E}-\Delta^{\psi}\left[1_{\mathrm{C}}\right]\right) \xi+(\gamma / 2) \xi_{\mathrm{i}}^{2}-\left(\mathrm{d}_{\mathrm{E}}-\Delta^{\psi}\left[\mathrm{l}_{\mathrm{C}}\right]\right) \xi_{\mathrm{i}} ; \\
& \mathrm{S}_{\xi}=\left(\xi-\xi_{\mathrm{i}}\right)\left[\mathrm{d}_{\mathrm{E}}-\Delta_{\mathrm{c}}-\gamma\left(\xi+\xi_{\mathrm{i}}\right) / 2\right] \quad \text { where } \gamma=\left(\Delta^{\psi}\left[\mathrm{l}_{0}\right]-\Delta^{\psi}\left[\mathrm{l}_{\mathrm{C}}\right]\right) / \ln \left(\mathrm{l}_{0} / \mathrm{l}_{\mathrm{c}}\right) ; \\
& \mathrm{S}_{\xi}=\ln \left[\left(\mathrm{d}_{\mathrm{d}} / \mathrm{l}_{\mathrm{i}}\right)^{\left.\mathrm{d}_{\mathrm{E}}-\bar{\Delta}_{\mathrm{\xi}_{\mathrm{i}}, \xi}\right] .}\right.
\end{aligned}
$$

With the mean fractal dimension between $\xi_{\mathrm{i}}$ and $\xi$ defined by $\bar{\Delta}_{\xi_{\mathrm{i}}, \xi}=\left(\Delta_{\xi_{\mathrm{i}}}+\Delta_{\xi}\right) / 2$, we can finally write

$$
S_{\xi}=\left(\xi-\xi_{\mathrm{i}}\right)\left(\mathrm{d}_{\mathrm{E}}-\bar{\Delta}_{\xi, \xi_{\mathrm{i}}}\right) \text {. }
$$

This equation leads to a local fractal dimension $\left(\psi_{\xi}=\mathrm{dS}_{\xi} / \mathrm{d} \xi=\mathrm{d}_{\mathrm{E}}-\Delta^{\psi}[\xi]\right)$, that varies linearly with the logarithmic scale coordinate $\mathrm{x}$ :

$$
\phi_{\xi}=d_{E}-\Delta^{\psi}[\xi] \text { with } \Delta^{\psi}[\xi]=\Delta^{\psi}\left[1_{c}\right]+\gamma \xi .
$$




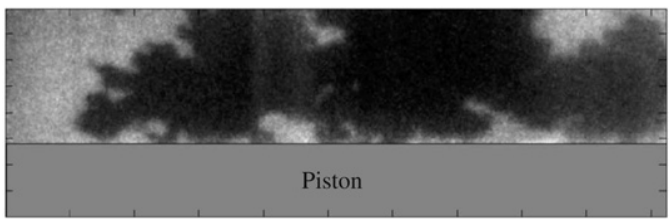

Fig. 4. Example of a turbulent flame near the piston.

\section{A general diffusion equation and the specific case of the parabolic scaling}

We can now generalise the equation for the evolution of scale-entropy, in cases where scale and wall-distance vary together with the the condition $\mathrm{l}_{\mathrm{i}}<\mathrm{d}_{\mathrm{d}}$ i.e. $\mathrm{x} \leq \xi$. The main variable is now noted $\mathrm{S}_{\mathrm{x}, \xi}$. It leads to

$$
\frac{\partial^{2} S_{x, \xi}}{\partial x^{2}}+\frac{\partial^{2} S_{x, \xi}}{\partial \xi^{2}}+\omega(x, \xi)=0 .
$$

If the scale-evolution follows a parabolic scaling $\left(\frac{\partial^{2} S_{x, \xi}}{\partial x^{2}}-\beta=0\right)$ and so does the multi-scale evolution with wall-distance $\left(\frac{\partial^{2} S_{x, \xi}}{\partial \xi^{2}}+\gamma=0\right)$, we then have the following expressions:

$$
\begin{aligned}
& \frac{\partial^{2} S_{x, \xi}}{\partial x^{2}}+\frac{\partial^{2} S_{x, \xi}}{\partial \xi^{2}}-(\beta-\gamma)=0 \\
& S_{x, \xi}=(\beta / 2) x^{2}+\left(\Delta\left[I_{c}\right]-d_{E}\right) x-(\gamma / 2) \xi^{2}-\left(\Delta^{\psi}\left[I_{c}\right]-d_{E}\right) \xi .
\end{aligned}
$$

The local fractal dimensions take the following forms:

$$
\begin{aligned}
& \Delta_{\mathrm{x}}=\mathrm{d}_{\mathrm{E}}+\phi_{\mathrm{x}}=\mathrm{d}_{\mathrm{E}}-\frac{\partial \mathrm{S}_{\mathrm{x}, \xi}}{\partial \mathrm{x}}=\Delta\left[\mathrm{l}_{\mathrm{c}}\right]+\beta \mathrm{x} ; \\
& \Delta_{\xi}^{\psi}=\mathrm{d}_{\mathrm{E}}-\phi_{\xi}=\mathrm{d}_{\mathrm{E}}-\frac{\partial \mathrm{S}_{\mathrm{x}, \xi}}{\partial \xi}=\Delta^{\psi}\left[\mathrm{l}_{\mathrm{c}}\right]+\gamma \xi .
\end{aligned}
$$

The local fractal dimensions $\Delta_{\mathrm{x}}$ and $\Delta_{\xi}^{\psi}$ are thus linear functions of respectively scale-logarithm and of the logarithm of wall-distance. Since scale-evolutivities are equal $(\beta=\gamma)$; we can finally write

$$
\frac{\partial^{2} S_{x, \xi}}{\partial x^{2}}+\frac{\partial^{2} S_{x \xi}}{\partial \xi^{2}}=0
$$

and

$$
\mathrm{S}_{\mathrm{x}, \xi}=(\beta / 2)\left(\mathrm{x}^{2}-\xi^{2}\right)+\left(\Delta\left[\mathrm{l}_{\mathrm{c}}\right]-\mathrm{d}_{\mathrm{E}}\right) \mathrm{x}-\left(\Delta^{\psi}\left[\mathrm{l}_{\mathrm{c}}\right]-\mathrm{d}_{\mathrm{E}}\right) \xi .
$$

For this latter case, taking $\Delta\left[\mathrm{l}_{\mathrm{C}}\right]=\Delta^{\psi}\left[\mathrm{l}_{\mathrm{C}}\right]=2$ and $\mathrm{d}_{\mathrm{E}}=3$ we derive

$$
\mathrm{S}_{\mathrm{x}, \xi}=(\xi-\mathrm{x})[1-\beta(\mathrm{x}+\xi) / 2] \quad \text { with } \mathrm{x} \leq \xi \text {. }
$$

\section{Experimental investigation on a corpus of turbulent flames obtained near a wall}

In order to use and verify some previous theoretical derivations, we would like to investigate turbulent flames experimentally and see, since fractal behaviour appears too crude, if one can find a simple behaviour, maybe a parabolic one, corresponding to a constant scale-evolutivity in scale-ranges and linear variations of local fractal dimensions with scale-logarithm or logarithm of wall-distance. Two types of measurements concerning the multi-scale structure can be done:

(i) We are interested in the evolution with scale of the "local fractal dimension" given by the box-counting method. It simply corresponds to the local slope of the quantity $\ln \left(\mathrm{N}\left[\mathrm{l}_{\mathrm{i}} ; \mathrm{l}_{0}\right]\right)$ as a function of scale $\mathrm{x}=\ln \left(\mathrm{l}_{\mathrm{i}} / \mathrm{l}_{\mathrm{c}}\right)$. This behaviour will be studied for flames far from the wall and near the wall (at the wall distance $d_{d}$ ) taking into account that, for the latter case, the relevant scale-range is reduced to $\left[l_{i} ; d_{d}\right]$.

(ii) The second kind of study is to follow the evolution of the "local fractal dimension" with wall distance and mainly at scales closer to the wall distance.

\subsection{Experimental configuration}

The research engine used for this experiment is a transparent SI engine developed by Renault [2]. It is a four valve pentroof chamber with a displacement volume of $500 \mathrm{~cm}^{3}$ and a compression ratio of 9.5 . To provide optical access within the 


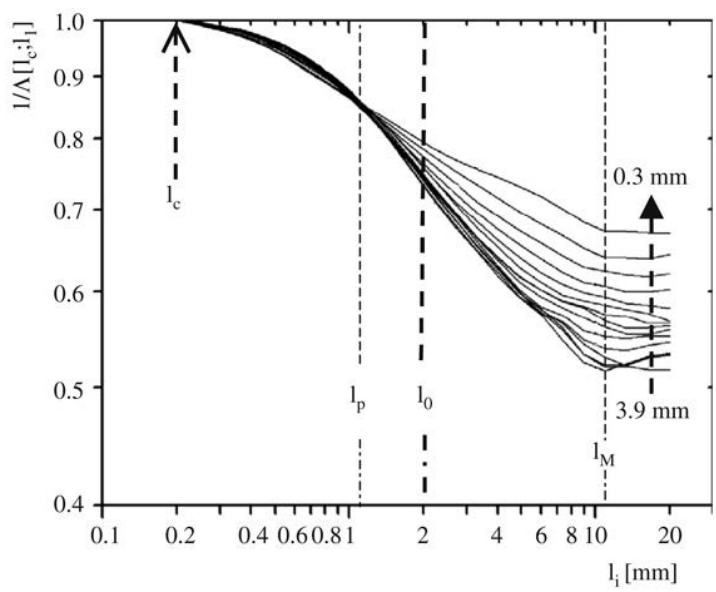

Fig. 5. Evolution of $\ln \left(1 / \Lambda\left[1_{c} ; l_{i}\right]\right)$ as a function of $x$ for wall-distances varying from $0.3 \mathrm{~mm} \leq \mathrm{d}_{\mathrm{d}} \leq 3.8 \mathrm{~mm}$. The arrow on the right indicates decreasing values of wall-distance from $3.9 \mathrm{~mm}$ to $0.3 \mathrm{~mm}$. Vertical dashed-lines indicates the inner cut-off scale $\mathrm{l}_{\mathrm{c}}$, the scale $\mathrm{l}_{\mathrm{p}}$ used for the measurement of $\Delta_{\xi}$, the integral scale $l_{0}$ and the outer cut-off scale $l_{\mathrm{M}}$.

combustion chamber, the piston is elongated and equipped with a quartz window ( $66 \mathrm{~mm}$ diameter). The cylinder head is bored and has two lateral windows. The engine is driven by an electric motor at $2000 \mathrm{rpm}$ and the intake air pressure is fixed at 500 mbar. In this study, the shape of the combustion chamber determines the aerodynamic field.

The turbulence was characterised from POD analysis of velocity fields obtained by PIV in previous studies: the turbulence intensity $\mathrm{U}^{\prime}=1.8 \mathrm{~m} / \mathrm{s}$, the average integral length scale $\mathrm{l}_{0}=2 \mathrm{~mm}$. So, the estimate of the micro-scale $\lambda$ and of the Kolmogorov length scale $\eta$ are respectively $0.3 \mathrm{~mm}$ and about $15 \mu \mathrm{m}$ [2]. Methane is continuously injected in the far upstream of the intake valves, to obtain an air-fuel mixture that is cyclically reproducible and as homogeneous as possible. The equivalent ratio is fixed to 1 , then the Lewis number is equal to 1 . To reduce the influence of residual burnt gases, the engine is fired only every 6 cycles. The electrodes of a conventional spark plug (gap spacing of $1 \mathrm{~mm}$ ) are aligned with the roof of the cylinder head. The ignition timing is fixed at 30 Crank-Angle-Degrees Before-Top-Dead-Centre (CAD BTDC) and the images are recorded at 15 CAD BTDC.

The thermodynamics conditions have been measured: the pressure at the CAD is equal to $P=9$ bar; the temperature is $600 \mathrm{~K}$. The laminar burning speed $\mathrm{U}_{\mathrm{L}}$, as a function of pressure, temperature and equivalence ratio, is calculated and gives $\mathrm{U}_{\mathrm{L}}=0.51 \mathrm{~m} / \mathrm{s}$. The laminar flame thickness is equal to $\delta=16.4 \mu \mathrm{m}$. We thus have a ratio $\mathrm{U}^{\prime} / \mathrm{U}_{\mathrm{L}}=3.53$. This implies a Damköhler number $D a=\left(\mathrm{l}_{0} / \delta\right) /\left(\mathrm{U}_{\mathrm{L}} / \mathrm{U}^{\prime}\right)$ equal to 35 and a Karlovitz number $K a=(\delta / \eta)^{2}$ equal to 0.6. Our corpus of flames (see an example in Fig. 4) belongs to the flamelet regime, meaning that the internal structure of the flames is not modified by the flow but is only wrinkled.

To determine the fractal parameters, we used laser tomography images obtained by Planar-Laser-Induced-Fluorescence of acetone, excited with a quadrupled Nd-Yag Laser ( $50 \mathrm{~mJ}$ energy, pulse duration $<10 \mathrm{~ns}$, laser sheet $\sim 0.5 \mathrm{~mm}$, wavelength: $266 \mathrm{~nm}$ ). The images (600 images, 12-bit images, $512 \times 120$ pixels $^{2}$ ) were recorded with an Intensified-CCD camera (Princeton-Pentamax), $10 \mathrm{~ns}$ after the laser pulse. The spatial resolution is $62.3 \mu \mathrm{m} /$ pixel (providing a field of view equal to $32.3 \times 7.6 \mathrm{~mm}^{2}$ ). For more details see Refs. [2,3].

Due to cyclic fluctuations generated on the front wrinkling for scales larger than the integral scale of turbulence, we proceed to a filtering of the scales larger than $\mathrm{l}_{0}$. This gives us the mean contour of the instantaneous front. The distance to the wall will be taken relative to this mean contour (see Fig. 2). For a specified scale, at each point of the instantaneous front, we measure the distance to the wall $d_{d}$, and the local linear roughness $\lambda\left[l_{c} ; l_{i}\right]$. Defining classes of wall distances $(0.2 \mathrm{~mm}$ range), we compute the mean roughness $\Lambda\left[1_{c} ; l_{i}\right]$ on all the balls with a wall distance belonging to this class. This procedure is repeated for each scale (the local roughness and the wall distance are measured). Our results are presented in the Fig. 5. It gives $\ln \left(1 / \Lambda\left[1_{c} ; l_{i}\right]\right)$ for wall distance varying from 0.3 to $3.9 \mathrm{~mm}$. We recall that the variation of $\ln \left(1 / \Lambda\left[1_{c} ; l_{i}\right]\right)$ versus $x$, gives the scaling behaviour of the front and namely the quantity $N\left[1_{i} ; l_{0}\right]$, since $1 / \Lambda\left[1_{c} ; 1_{i}\right]=\left(1 / \Lambda\left[1_{c} ; l_{0}\right]\right) N\left[1_{i} ; 1_{0}\right]\left(l_{i} / l_{0}\right)($ Eq. (4)). More exactly, the local slope gives access to $1-\Delta_{x}$. The scale analysis $\left(\ln \left(1 / \Lambda\left[l_{c} ; l_{i}\right]\right)\right.$ versus $\left.x\right)$ shows clearly that the flame cannot be considered as a fractal, since there is no straight linear part on the ln-ln curve. One can verify that the outer cutoff $l_{M}$ is close to $11 \mathrm{~mm}$. The integral scale seems to divide the curve into two symmetrical parts. Let us now analyse more closely how the local fractal dimension $\Delta_{\mathrm{X}}$ (the local slope of the curve is exactly $1-\Delta_{\mathrm{X}}$ ) evolves with scale.

\subsection{The multi-scale structure of flames far from the wall $\left(\mathrm{d}_{\mathrm{d}}>\mathrm{l}_{0}\right)$ : The fractal dimension is a scale-dependent quantity}

The multi-scale structure of flames far from the wall is investigated (with $2 \mathrm{~mm}<\mathrm{d}_{\mathrm{d}} \leq 3.9 \mathrm{~mm}$ ). The flame displays a scale-dependent behaviour of fractal dimension. We thus determine the local fractal dimension $\Delta_{\mathrm{X}}$ as a function of the scale logarithm, which is given by the local slope (the slope gives more exactly the quantity $1-\Delta_{x}$ ) of $\ln \left(1 / \Lambda\left[1_{c} ; 1_{i}\right]\right.$ ) versus $\mathrm{x}$. 


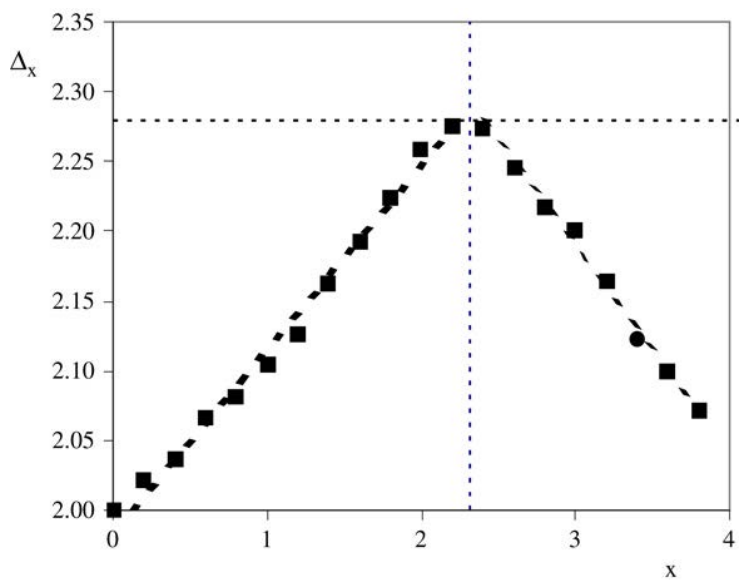

Fig. 6. Local fractal dimension $\Delta_{\mathrm{x}}$ as a function of scale logarithm $\mathrm{x}$. The linear fit corresponding to the first zone $\left[\mathrm{l}_{\mathrm{c}} ; \mathrm{l}_{0}\right]$ leads to $\Delta_{\mathrm{x}}=0.13 \mathrm{x}+1.99$. The linear fit in the symmetrical zone gives $\Delta_{\mathrm{x}}=0.15 \mathrm{x}+2.63$. Vertical dashed line indicates the integral scale. The horizontal dashed line indicates the value $\Delta_{\mathrm{F}}^{*}=2.28$ derived by using Ref. [14].

The evolution of the local fractal dimension as a function of the scale logarithm $\mathrm{x}$ (Fig. 6) reveals two distinct zones showing a transition at the integral scale: (i) the local fractal evolution increases with the scale logarithm from 2 to a maximum value around 2.28 . This maximum is close to the value $\Delta_{\mathrm{F}}^{*}=2.28$ calculated using a slightly modified version of North and Santavicca's expression [14].

(ii) The local fractal dimension decreases beyond a scale corresponding to the integral scale. The integral does divide the curve in two parts. Let us consider the first zone, i.e. the part that corresponds to the scale-range [ $1_{c} ; l_{0}$ ]. It can be approximated by a linear behaviour, whose slope is $\beta=0.13$. This linear behaviour would correspond to the parabolic case, which implies a local dimension linear with the scale-logarithm. Let us note that the second zone can also be approximated by a linear law with a slope of 0.147 , close to the first one. We thus conclude that multi-scale behaviour of turbulent flames at distances larger than the integral scale is well approximated by two symmetrical zones following parabolic scaling. We emphasise the fact that parabolic scaling can only be an approximation, since one cannot have a rough break in the slope in Fig. 6 but, taking into account all the experimental uncertainties that such measurements imply and the simple assumption we did through constancy of scale-evolutivity, parabolic scaling is reasonably verified in our experimental results.

\subsection{The multi-scale structure of flames near the wall $\left(\mathrm{d}_{\mathrm{d}}<\mathrm{l}_{0}\right)$ : Variation of fractal dimension with wall-distance}

We studied the multi-scale structure of flames near the wall (with $0.3 \mathrm{~mm} \leq \mathrm{d}_{\mathrm{d}} \leq 2 \mathrm{~mm}$ ), for wall distances smaller than the integral scale $l_{0}$. The relevant scale-range becomes $\left[l_{c} ; d_{d}\right]$, since scales larger than $d_{d}$ have no effect on the front. We need to measure the local fractal dimension at the scale $d_{d}$; this is given by the local slope of the scale analysis but, due to experimental uncertainties which increase with scale, this is rather difficult. So we choose a relatively small scale-range $\left[l_{p} ; d_{d}\right]$ and we determine, for this scale-range, the mean slope leading to a measured value $D_{f, m}\left(d_{d}\right)$. This is, in fact, a mean value since, at is already known, the scale analysis is not linear and the front is not fractal. At a preliminary stage, we can assume that this value corresponds to $\Delta\left[\mathrm{d}_{\mathrm{d}}\right]$. But it is possible to be more precise when the fact that scale analysis follows parabolic scaling is considered. The mean fractal dimension $\mathrm{D}_{\mathrm{f}, \mathrm{m}}\left(\mathrm{d}_{\mathrm{d}}\right)$ is measured in a seemingly linear part from a scale $\mathrm{l}_{\mathrm{p}}$, and the scale corresponding to wall-distance $\mathrm{d}_{\mathrm{d}}$; if we consider a parabolic scaling, this measured dimension can be written $\mathrm{D}_{\mathrm{f}, \mathrm{m}}\left(\mathrm{d}_{\mathrm{d}}\right)=\left(\Delta\left[\mathrm{l}_{\mathrm{p}}\right]+\Delta\left[\mathrm{d}_{\mathrm{d}}\right]\right) / 2$. Since $\Delta\left[\mathrm{l}_{\mathrm{p}}\right]$ is known, thanks to our previous scale analysis (it can be measured more easily since uncertainty on local slope is smaller at small scales), by measuring $\mathrm{D}_{\mathrm{f}, \mathrm{m}}\left(\mathrm{d}_{\mathrm{d}}\right)$, we can determine $\Delta\left[\mathrm{d}_{\mathrm{d}}\right]$. The value of $\Delta\left[\mathrm{d}_{\mathrm{d}}\right]$ noted $\Delta_{\xi}$ with $\xi=\ln \left(\mathrm{d}_{\mathrm{d}} / \mathrm{l}_{\mathrm{c}}\right)$ is measured for our corpus of flames. We took $\mathrm{l}_{\mathrm{p}}=1.1 \mathrm{~mm}$ which corresponds to $\Delta\left[\mathrm{l}_{\mathrm{p}}\right]=2.2$. This point corresponds to the one towards which all the curves seem to converge (see Fig. 5 ). Beyond this point, these curves display an identical small scale behaviour. We observe (Fig. 7) that the local dimension has a linear evolution with $\xi$ until the value of $\xi$ corresponding to the integral scale (the slope is 0.13 ); this is followed by a saturation of fractal dimension around 2.29-2.30 (close to the value $\Delta\left[\mathrm{l}_{0}\right]^{*}=2.28$ ) for a wall-distance larger than the integral scale.

Finally, we represent in Fig. 8, the local fractal dimensions for scales and wall-distances smaller than the integral scale. The two curves are similar. The global linear fit gives 0.124 , which is very close to the value $\beta^{*}=0.122$ calculated using Ref. [14]. We can conclude that the local fractal dimension is linearly dependent on the scale-logarithm and on the logarithm of the wall-distance.

\section{Conclusion}

As a conclusion, we introduced a new geometrical framework, based on scale-entropy and a scale-entropy diffusion equation to describe the multi-scale features of turbulent flames in the vicinity of a wall. In order to define the departure of 


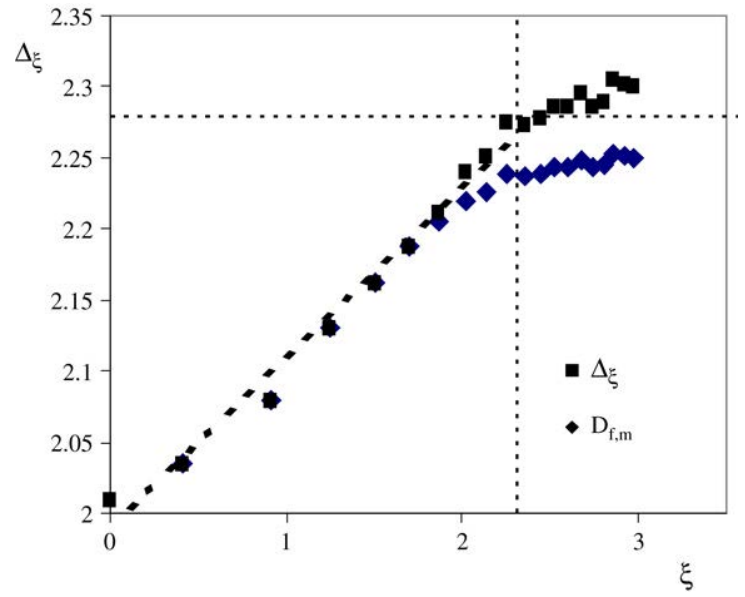

Fig. 7. Mean dimension $\mathrm{D}_{\mathrm{f}, \mathrm{m}}\left(\mathrm{d}_{\mathrm{d}}\right)$ over $\left[\mathrm{l}_{\mathrm{p}} ; \mathrm{d}_{\mathrm{d}}\right]$ and local fractal dimension $\Delta_{\xi}$ as a function of scale logarithm $\xi\left(\right.$ with $\mathrm{D}_{\mathrm{f}, \mathrm{m}}\left(\mathrm{d}_{\mathrm{d}}\right)=\left[\left(\Delta\left[\mathrm{l}_{\mathrm{p}}\right]+\Delta_{\xi}\right) / 2\right]$. Vertical dashed line indicates the integral scale. The linear fit (for wall distances belonging to $\left[l_{c} ; l_{0}\right]$ ) gives $\Delta_{\xi}=0.12+1.99 \xi$. The horizontal dashed line indicates the value $\Delta_{F}^{*}=2.28$ derived by using Ref. [14].

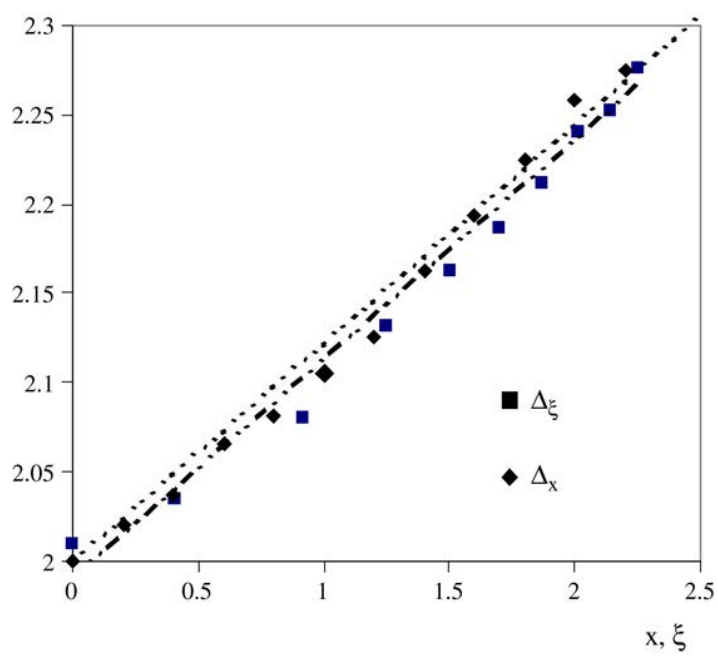

Fig. 8. Local fractal dimensions $\Delta_{\mathrm{x}}$ and $\Delta_{\xi}$ as a function respectively of $\mathrm{x}$ and $\xi$ for $\mathrm{l}_{\mathrm{i}}$ and $\mathrm{d}_{\mathrm{d}}$ varying in $\left[\mathrm{l}_{\mathrm{c}} ; \mathrm{l}_{0}\right]$. The linear fit with all points gives a slope 0.124 and is indicated by the thicker dashed-line. The other dashed-line indicates the slope corresponding to the value $\beta^{*}=0.122$ derived using Ref. [14].

a multi-scale system from pure scale invariance, we introduced the notion of scale-evolutivity which, for the general case, depends on the scale and the wall distance. We studied the particular case ("parabolic scaling") in which scale-evolutivity is a constant. A specific behaviour of turbulent flames is expected for such a case, namely that the local fractal dimension should follow a linear variation with the logarithm of scale, and the logarithm of wall distance. We found that real turbulent flames near a wall are close to this particular case, with a scale-evolutivity equal to 0.12 . The general case gives us a diffusion equation for scale-entropy which is directly linked to the flame roughness, i.e. to the turbulent flame velocity. We would like to investigate the ability of this equation to be used for a new kind of geometrical modelisation of turbulent flames in the vicinity of a wall.

\section{Acknowledgements}

D. Queiros-Conde thanks Professor W. Fürst for his encouraging support and Sezin Topçu for her help and useful discussions. Part of this work has been funded by a contract between DGA and ENSTA (Ref. RA 07007).

\section{References}

[1] F. Nicolleau, C.R. Acad. Sci 319 (Série II) (1994) 873.

[2] F. Foucher, Ph.D. Thesis, Univ. of Orléans, 2002.

[3] F. Foucher, C. Mounaïm-Rousselle, Comb. Flame 143 (2005) 323. 
[4] H.J. Catrakis, P.E. Dimotakis, J. Fluid Mech. 317 (1996) 369

[5] A. Pocheau, D. Queiros-Conde, Phys. Rev. Lett. 76 (1996) 3352.

[6] D. Queiros-Conde, Ph.D. Thesis, University of Provence, Marseille, France, 1996

[7] D. Queiros-Conde, Proc. R. Soc. Lond. A 459 (2003) 3043.

[8] D. Queiros-Conde, M. Feidt, Int. J. Thermodynamics 11 (2008) 11.

[9] A. Bejan, S. Lorente, J. Appl. Phys. 100 (2006) 041301. See also A. Bejan, Shape and Structure, from Engineering to Nature, Cambridge University Press, 2000.

[10] A.N. Kolmogorov, Dokl. Akad. Nauk. SSSR 30 (1941) 9; Dokl. Akad. Nauk. SSSR 32 (1941) 538.

[11] A.R. Kerstein, Comb. Sci. Tech. 60 (1988) 441.

[12] D. Queiros-Conde, C. R. Acad. Sci. t. 327 (série II b) (1999) 1385; Phys. Rev. E 64 (2001) 015301(R).

[13] J. Mantzaras, P.G. Felton, F.V. Bracco, Comb. Flame 77 (1989) 295.

[14] G.L. North, D.A. Santavicca, Comb. Sci. Tech. 72 (1990) 215.

[15] D. Queiros-Conde, J. Bonjour, W. Wechsatol, A. Bejan, Physica A 384 (2007) 719. 